\title{
Ultrastructural and Morphometric Analysis of the Separation of Two Thigh Muscles in the Chick
}

\author{
SALLY SCHROETER AND KATHRYN W. TOSNEY \\ Department of Biology, The University of Michigan, Ann Arbor, Michigan 48109-1048
}

\begin{abstract}
Limb muscles separate from one another in a complex but highly stereotyped sequence and spatial pattern. The process of separation is characterized by the progression of a region of increased extracellular space, the cleavage zone, along the proximodistal axis between the individual muscle anlagen. We analyzed ultrastructurally the muscles and cleavage zone during the separation of two representative muscles, the developing sartorius and iliotibialis in the chick thigh, to establish an accurate baseline for an analysis of the mechanisms of separation. Comparisons of the morphology and distribution of cells before and after separation show no evidence that muscles became separated by the massive influx of an exterior cell population; if populations invade the cleavage zone, they are small. We do find characteristic transitions within the cell population of the cleavage zone in situ that could accomplish cleavage without invoking massive cell movements. These progressive transitions within the cleavage zone include a loss of close cell-cell interactions, an increase in extracellular space, the assumption of a more stellate morphology by mesenchyme cells, and a gradual alteration in the composition of the extracellular matrix from one typical of early muscle to one typical of loose connective tissue. Myotubes do differentiate between the incipient muscles, ruling out the possibility that the location where muscles will separate is defined by sites where myotubes fail to differentiate. Instead, the myotubes in the cleavage zone gradually diminish in number and appear to be specifically recognized and removed from the cleavage zone by phagocytes. We suggest that the transitions within the cleavage zone, including the loss of muscle cells, are a result of the progressive differentiation of loose connective tissue. If so, then the spatial pattern and process of cleavage is a consequence of spatially programmed cell differentiation.
\end{abstract}

\section{INTRODUCTION}

The morphogenesis of limb muscles is similar in representatives of several classes of vertebrates, including the mouse (Lance Jones, 1979), axolotl (Grim and Carlson, 1974), human (Čihák, 1972), lizard (Romer, 1942), and chick (Romer, 1927; Wortham, 1948; Sullivan, 1962; Shellswell and Wolpert, 1977; Pautou et al.,
1982; Schroeter and Tosney, 1989, 1991). In all of these species, the muscles of the limb are sculpted from two muscle masses, condensations of cells that lie dorsal and ventral to the cartilaginous anlage that will form the central bone(s) of each limb segment. Individual muscles separate from one another in a stereotyped temporal sequence and in a stereotyped spatial pattern that can be monitored in serial cross sections of the limb during the period of separation. The region of separation is characterized at the light microscopic level by a gradual increase in the extracellular space among cells in the cleavage zone, the region between separating muscles.

Despite the ease of characterizing the gross spatial differences associated with muscle separation, the morphogenetic mechanisms that cause the muscles to separate have yet to be identified. Previous studies have, however, ruled out some possibilities. It is clear that muscle separation is not a side effect of the general maturation of the limb since the muscles do not separate in a constant and simultaneous proximal to distal order, unlike other aspects of limb maturation in which tissues are determined and mature from proximal to distal. Instead, each muscle separates in a characteristic spatial pattern, some separating from distal to proximal while others separate from proximal to distal (see Romer, 1927; Schroeter and Tosney, 1991). Muscle separation, therefore, is subject to complex spatial-temporal control that is separate from general maturation processes. In addition, motor nerves (Paterson, 1888; Shellswell and Wolpert, 1977; Shellswell, 1977; Harrison, 1905), tensile forces imposed by skeletal growth (Carey, 1920; Shellswell and Wolpert, 1977), a prepatterning by vasculature (Caplan and Koutroupas, 1973; Wilson, 1986), and a prespecification of myogenic precursors to become parts of particular muscles (Chevallier and Kieny, 1982; Lance-Jones, 1988a,b) have all been shown to be unlikely to cause muscle cleavage. The separation of muscles is currently thought to be an autonomous process carried out by those cells within or near the muscle masses, and the patterning is generally considered to make use of a postulated three-dimensional system of positional information (see Shellswell and Wolpert, 1977).

The present investigation addressed the mechanism of muscle separation by analyzing the separation of two

Received October 29, 1990. Accepted March 25, 1991.

Sally Schroeter is now at Department of Physiology, Emory University, Atlanta, GA 30322 . Address reprint requests there. 
chick thigh muscles, the sartorius and iliotibialis, ${ }^{1}$ at the ultrastructural level. These muscles can be identified easily during the entire 2-day period when they are separating along the distal to proximal axis because they are large and superficial, and extend the full length of the thigh. We were particularly interested in determining whether differences in the distribution, spacing, or morphology of distinct cell types either presaged cleavage or were correlated with the progression of the cleavage zone between these muscles. The distribution and morphology of mesenchyme cells was of particular interest, because these cells have been implicated in the establishment of the pattern of muscle separation; and it is not known whether they establish this pattern indirectly by providing positional information in the limb or more directly by actively separating muscles in some way (Jacob and Christ, 1980; Chevallier and Kieny, 1982; Noden, 1983; Lance-Jones, 1988c). For instance, indirect evidence has suggested that mesenchyme cells may actively separate muscles by migrating between their anlagen and synthesizing abundant extracellular matrix (Shellswell and Wolpert, 1977; see also Chiquet et al., 1981). Alternatively, cleavage has also been suggested to result directly from a variety of possible (but yet to be documented) changes in the myogenic cells. For instance, myogenic cells might not differentiate within cleavage zones (Noakes et al., 1986), or might stop or reverse their differentiation (Shellswell, 1977; Shellswell and Wolpert, 1977); or their adhesivity might decrease and result in the sorting out of cells and the separation of muscles (see Shellswell and Wolpert; 1977). To address these possible mechanisms, we systematically sampled populations in the region of muscle separation before, during, and after separation and characterized them ultrastructurally. We also tested for statistically significant changes in the distribution, spacing, and morphology of distinct cell types.

A preliminary account of this work has appeared (Schroeter and Tosney, 1987).

\section{MATERIALS AND METHODS \\ Fixation, Histology, and Electron Microscopy}

An initial group of embryos was prepared for light microscopy to enable us to use published criteria to identify the appropriate embryonic stages and to establish initial criteria for cleavage phases. Stage 26 through 32.5 (Hamburger and Hamilton, 1951) White Leghorn chicken embryos were fixed sequentially in Carnoy's and Bouin's fixatives (Humason, 1972), dehydrated in graded ethanols, embedded from xylenes into paraplast, transversely sectioned at $12 \mu \mathrm{m}$, and stained with Alcian blue, cresyl violet, and eosin. Tissues were easily distinguished by color and allowed us to establish characteristics such as cell densities and shapes to identify the same tissues in the monochromatic, plastic sections.

${ }^{1}$ The generally accepted modern names for muscles are listed in Nomina Anatomica Avium (Baumel et al., 1979). The modern names for the two muscles used for the present study are in parentheses as follows: sartorius (iliotibialis cranialis) and iliotibialis (iliotibialis lateralis). The terminology used throughout the present paper is, however, that used by Romer (1927) in order to be consistent with previous studies to which the current information is most relevant.
The majority of the analyses used plastic-embedded embryos. Stages 27-32 embryos were decapitated, eviscerated, and cut in half sagittally; and the feet and tail were removed. The remaining portion of the limb was fixed for $3-15 \mathrm{hr}$ at $4^{\circ} \mathrm{C}$ in $2.5 \%$ glutaraldehyde, $0.15 \mathrm{M}$ sodium cacodylate, and $0.1 \%$ tannic acid. The latter was added to enhance the preservation of glycosaminoglycans (Singley and Solursh, 1981). The tissues were postfixed in cacodylate-buffered $2 \%$ osmium tetroxide, dehydrated in graded ethanols, and embedded from propylene oxide into Epon-Araldite. The blocks were polymerized at $60^{\circ} \mathrm{C}$ and serially sectioned at $15 \mu \mathrm{m}$ transverse to the long axis of the limb as in Tosney and Landmesser (1986).

Equivalent thick sections in the center of each phase of cleavage in 7 stage 27.5-29 embryos were selected for ultrastructural study. This method ensured a repeatable mode of collecting data from a location well inside each phase, allowed results to be compared between embryos, and assured that samples did not contain regions where tendons develop. Camera-lucida drawings of the selected thick sections were made before thin-sectioning for later orientation. Thin sections were taken from the selected thick sections as in Tosney and Landmesser (1986); mounted on Formvarcoated, 1,000- $\mu \mathrm{m}$, single-hole grids; stained with uranyl acetate and lead citrate; and viewed on a Philips 300 electron microscope. Photographic montages of the sartorius and iliotibialis muscles and the area between them were prepared at low and high magnifications.

\section{Morphometry and Statistical Analyses}

Photographic montages from 7 embryos in which sections from 2 or 3 different phases of cleavage could be obtained from the same thigh were used for morphometric analysis. A circular sample region with a radius of $20 \mu \mathrm{m}$ was drawn in 6 types of locations: within the muscles and within the cleavage zone during each of the 3 phases of cleavage. Each type of sample area closely represented an equivalent region in each embryo. We defined 3 measurements that are two-dimensional estimates of cell density in the 6 regions: number of cells, defined as the total number of all cells within each sample area; number of muscle cells, defined as the number of all cells meeting our criteria for muscle cells (see Results) within each sample area; and number of mesenchyme cells, defined as the number of all cells meeting our ultrastructural criteria for mesenchyme cells (see Results) within each sample area. We determined the distributions of muscle and mesenchyme cells since they are clearly the largest cell populations at this time in development. The percentage of extracellular space was determined by using a Zeiss MOP-3 digitizer to measure the area of all cells (including all processes) within each sample area, subtracting this total cellular area from the total sample area, and expressing the result as a percentage of the sample area. Paired t-tests were used to determine if each of the measurements showed significant differences between types of sample areas. The data for each location were paired only within the same embryo to eliminate any influence of variation between embryos. The criterion for statistical significance was $P<0.05$.

To quantify changes in cellular morphology, we counted the number of mesenchyme cell processes (pro- 
cesses connected to mesenchyme cells and longer than $1 \mu \mathrm{m}$ ), the number of muscle cell processes (those connected to muscle cells and longer than $1 \mu \mathrm{m}$ ), and the number of isolated filopodia (cell processes that could not be traced to cells) in each sample area. A 2-way analysis of variance controlling for location (within muscle or cleavage zone) and phase (cleaved or uncleaved) was used to test for significant difference in these data. The area of the muscle groups before and after cleavage was also obtained from camera-lucida tracings at the light-microscopic level and compared by superimposing the drawings.

\section{Immunohistochemistry}

Stage 27-29 embryos were fixed for $1 \mathrm{hr}$ in $2 \%$ paraformaldehyde in phosphate-buffered saline (PBS) with $0.5 \%$ cetylpyridinium chloride at room temperature, rinsed in 5\% sucrose, incubated in $20 \%$ sucrose, and embedded and frozen in OCT (Tissue Tek). Each thigh contained a piece of hair inserted underneath the ectoderm, parallel to the femur, to enable perpendicular orientation when sectioning. Transverse sections were cut on an American Optical cryostat at $6-8 \mu \mathrm{m}$, mounted on acid-cleaned slides double-subbed with gelatin, and stored at $-80^{\circ} \mathrm{C}$ for up to 2 weeks. Every tenth to eleventh section was stained with cresyl violet to enable the selection of sections that contained examples of the three phases of cleavage.

The distribution of differentiating muscle cells was determined using MF 20 (1:10 dilution), a monoclonal antibody to the myosin heavy chain and light meromyosin that is typical of sarcomeres (Bader et al., 1982; Shimizu et al., 1985). This antibody was also used as a positive control. The distribution of various extracellular matrix (ECM) molecules was examined using the following monoclonal antibodies at a dilution of 1:50 unless otherwise stated. Antibody $2 \mathrm{~B} 6$ is specific for a 4-sulfated epitope generated by digestion of chondroitin-4-sulfate and dermatan sulfate with chondroitinase ABC (Caterson et al., 1985; Sorrell et al., 1988). Antibody 3B3 (1:100 dilution) is specific for a 6-sulfated epitope generated by digestion of chondroitin sulfate proteoglycans with chondroitinase ABC (Caterson et al., 1985; Sorrell et al., 1988). Antibody 5D4 is specific for keratan sulfate (Caterson et al., 1983; Sorrell et al., 1988). Antibody CS-56 is specific for chondroitinsulfate proteoglycan without chondroitinase pretreatment (Avnur and Geiger, 1984). All antibodies were the generous gift of Jim Dennis.

The selected sections were blocked in $1 \%$ bovine se-

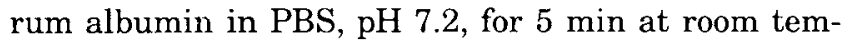
perature; incubated with primary antibody for $1 \mathrm{hr}$ at $37^{\circ} \mathrm{C}$; rinsed in PBS for $10 \mathrm{~min}$; and blocked again. Biotinylated secondary antibodies were applied for 30 min at room temperature (3B3: 1:50 goat anti mouse IgM from Organon Teknika Corp.; 2B6, 5D4, CS-56, MF 20: 1:40 sheep anti mouse IgG from Amersham). The sections were rinsed, blocked, and then incubated for $30 \mathrm{~min}$ with Texas Red-avidin (1:50, Amersham) and rinsed. The primary antibody was omitted from some sections in each group as a control. Sections stained with $3 \mathrm{~B} 3$ and $2 \mathrm{~B} 6$ were pretreated with chondroitinase $\mathrm{ABC}$ for $30 \mathrm{~min}$ at $37^{\circ} \mathrm{C}(0.1 \mathrm{units} / \mathrm{ml}$, Seikagaku Kogyo Co., Ltd., Tokyo); sections untreated with chondroitinase served as controls. Protease inhibitors
(10mM EDTA, 5mM benzamidine, 0.11M 6-aminocaprolic acid, and $0.1 \mathrm{mM}$ phenylmethylsulfonyl fluoride) were included with the chondroitinase treatments.

\section{RESULTS}

Identification and Progression of the Cleavage Zone

The gradual separation of two muscles is diagrammed in Figure 1 to help the reader visualize the spatial-temporal progression of the separation process and our methods of sampling that process. At stage 27.5 , the distal region of the iliotibialis and sartorius are distinctly separate, while the proximal regions have yet to show any evidence of separation. The region of separation, the cleavage zone, progresses proximally until each muscle is fully distinct along the entire proximodistal axis during stage 30 . The process is a smooth one; and in embryos between these stages, sequential phases of cleavage are spatially arrayed along the distal to proximal axis within single thighs. In order to sample regions that had separated to different degrees systematically, we first established the timing of the distal to proximal progression of the cleavage zone between the sartorius and iliotibialis muscles by plotting the proportion of the sartorius that remained uncleaved at different stages of development (Fig. 2). We then concentrated on thighs between stages 27 and 30 , which display phases from an uncleaved or cleaving state to fully separated muscles in a single thigh.

The phases of cleavage we defined as uncleaved, cleaving, and cleaved are illustrated in light and electron micrographs in Figure 3. In the uncleaved phase (Fig. 3A,D), there is no obvious distinction between the two muscles at the light microscopic level; this phase is characterized by a uniform distribution of cells in both of the muscles and in the area of future separation, the incipient cleavage zone. More distally in the thigh, the muscles are neither clearly separated nor are they indistinguishable; there appears to be more extracellular space between cells in the cleavage region than in either adjacent muscle, and the cleavage zone displays a continuum of increasing extracellular space along the proximal to distal axis. A central section taken from this region is used to characterize the cleaving phase (Fig. 3B,E). In the cleaved phase, the cells of the two muscles proper are uniformly closely packed and are obviously separated by a mature cleavage zone in which cells are less closely packed and extracellular space is more extensive (Fig. $3 \mathrm{C}, \mathrm{F}$ ). We analyzed only sections in the proximodistal center of uncleaved, cleaving, and cleaved phases in each thigh to assure that we were examining equivalent phases of cleavage in different embryos.

\section{Cell Types and Their Organization Within Muscles}

We were particularly interested in determining whether differences in the distribution of particular populations of cells characterized the process of cleavage. We initially concentrated on two ultrastructurally identifiable cell types which were common in the muscle masses during the relevant stages of development. The first, differentiating muscle cells, have ultrastructural characteristics as previously described in younger embryos by Hilfer et al. (1973). These cells have myofilaments, numerous clusters of ribosomes, 


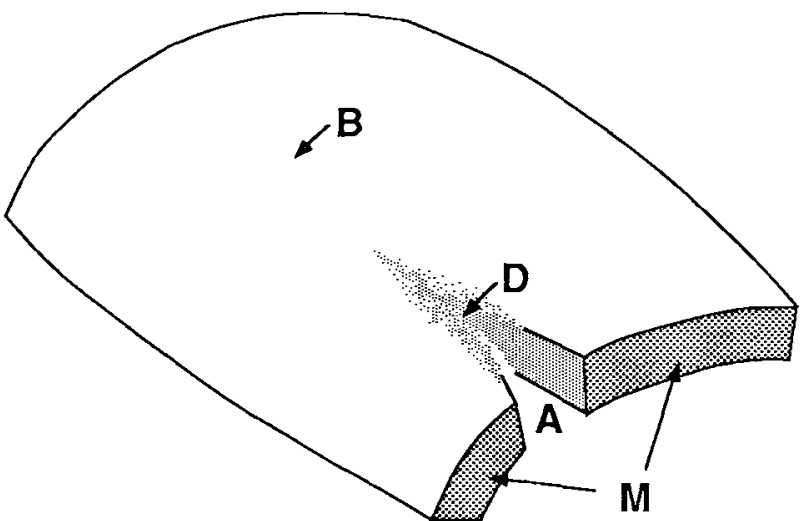

Stage $\mathbf{2 7 . 5}$

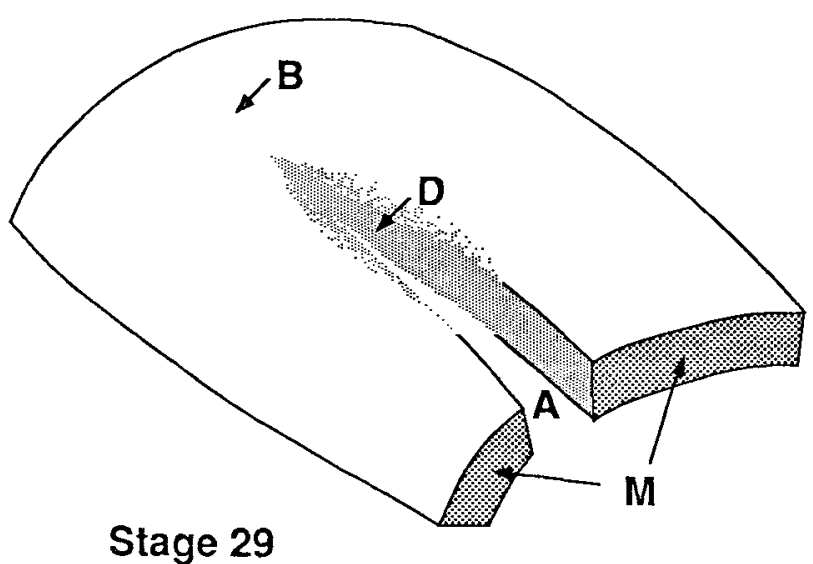

Stage 29

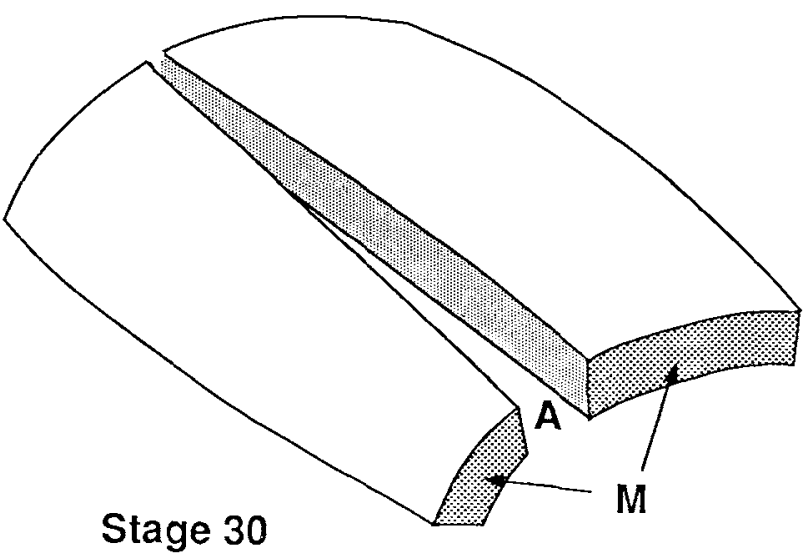

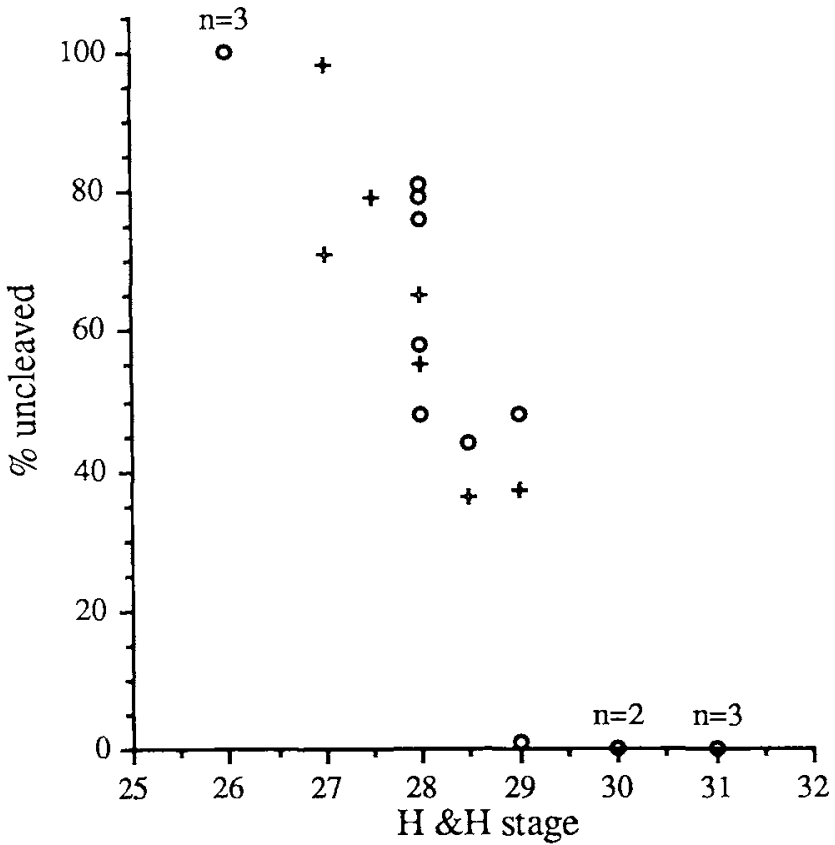

Fig. 2. Progression of the cleavage zone and embryonic stage. The progression of the cleavage zone between the sartorius and iliotibialis muscles was characterized by examining serial transverse sections of 23 thighs from stages 26 to 31 . The $Y$ axis shows the length of the uncleaved portions of the sartorius muscle, standardized for embryos of different sizes and ages, as a percentage of the total muscle length. The $\mathrm{X}$ axis is the Hamburger and Hamilton (1951) embryonic stage. Cleavage started during stage 27 , progressed along the distal to proximal axis of the thigh, and was complete during stage 30 . Those embryos examined ultrastructurally are indicated by $a+$.

and a smooth profile; are less electron dense than other cells; and are generally closely apposed to other cells over most of their surfaces (Fig. 4A). A related cell type is rare and is identical to the muscle cells in these respects, except for the absence of myofilaments and a somewhat thinner rim of cytoplasm over the nucleus (Fig. 4A). These are likely to be developmentally younger muscle cells or myotubes in which the plane of section was through an area devoid of myofilaments, and they were counted as muscle cells in the morphometric analysis. The second cell type displays characteristics typical of mesenchyme cells, including an irregular and elongated shape, abundant rough endoplasmic reticulum, and an oval nucleus sur-

Fig. 1. Diagram of the progression of the cleavage zone. The progressive separation of the iliotibialis (right) and sartorius (left) muscles is diagrammed to aid in the visualization of the spatial-temporal patterns of separation. In each diagram, distal is in the foreground, where the separation process begins. Phases of cleavage are indicated by letters: A: After cleavage, the cleaved phase. D: During cleavage, the cleaving phase. B: Before cleavage, the uncleaved phase. The position of letters illustrates where thin sections would be taken to sample populations in each phase. At stage 27.5 the distal regions of the two muscles (M) are distinctly separate but the more proximal regions are in the uncleaved phase and show no evidence of separation. The cleavage zone progresses proximally, and all three phases of cleavage are arrayed within a single thigh at stage 29 . The separation process is complete during stage 30 . 

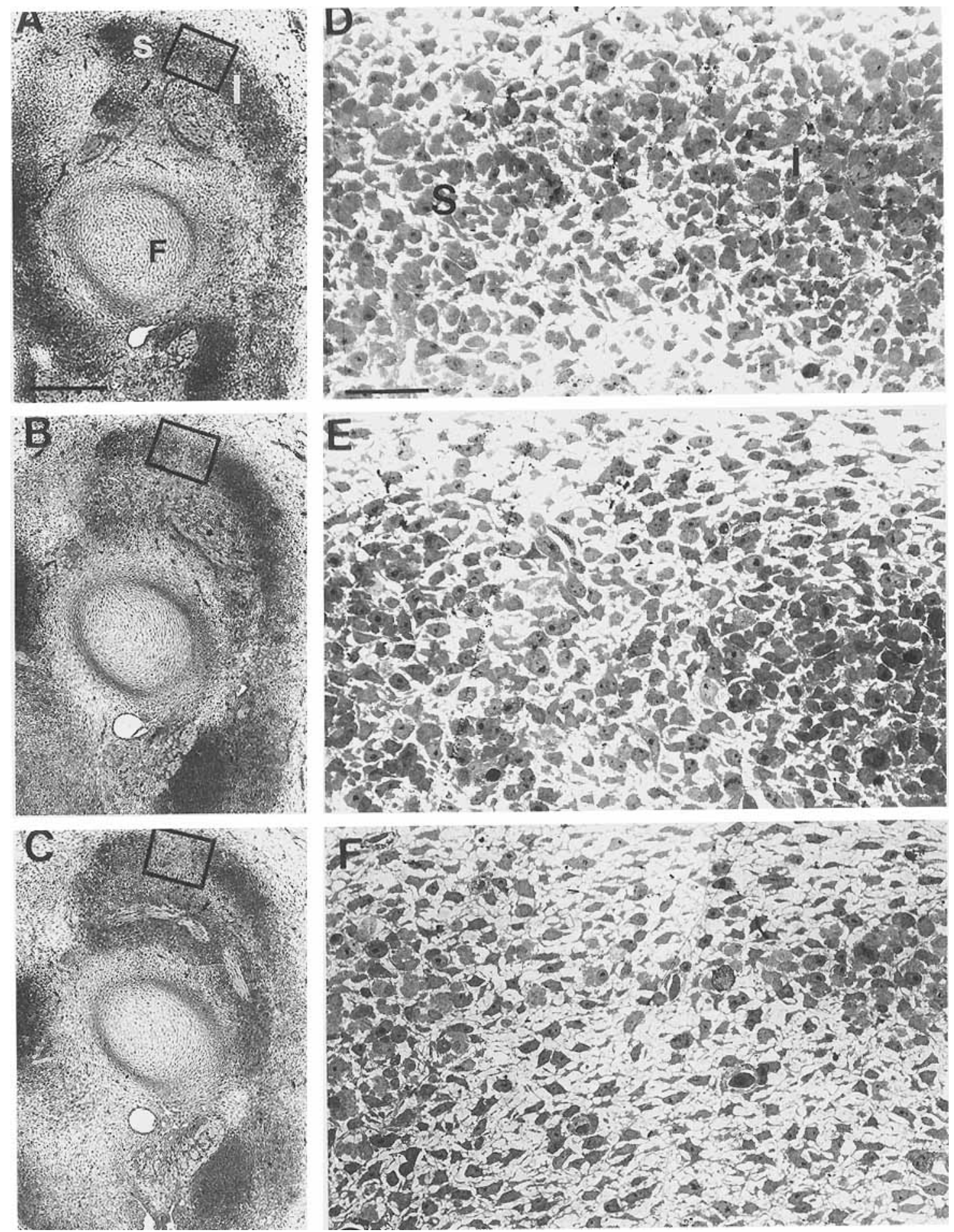

Fig. 3. Phases of cleavage between sartorius and iliotibialis muscles. Incipient muscles are separated by cleavage zones, regions of lower cell density that progress in a characteristic proximodistal or distoproximal direction as illustrated in these micrographs of a stage 28 chick thigh. Anterior is up and dorsal to the right. The darker condensations of cells are the developing muscles that surround the femur $(\mathrm{F})$. The iliotibialis (I) is a broad, sheet-like muscle covering the dorsal part of the thigh, and the sartorius (S) is a smaller muscle located at the anterior edge of the iliotibialis. Three phases of cleavage between the sartorius and iliotibialis are shown (boxed regions) in light micrographs of $15-\mu \mathrm{m}$ plastic sections $(\mathbf{A}-\mathbf{C})$ and in electron micrographs of the same area of each section (D-F). A,D: Uncleaved phase. The cell density and proportion of extracellular space within the incipient cleavage zone is indistinguishable from that within the two muscle areas in the proximal region of the thigh at the light level, although a slight qualitative difference is visible at the ultrastructural level. B,E: Cleaving phase. At an intermediate level along the proximodistal axis, the proportion of extracellular space within the cleavage zone has increased, and the cells in the cleavage zone appear to be less densely packed than in either adjoining muscle. C.F: Cleaved phase. Cleavage between the sartorius and iliotibialis begins distally and is complete in this section. The condensations of muscle cells are obviously separated by an area of increased extracellular space. Bar for $A-C=200 \mu \mathrm{m}$; for $D-F=25 \mu \mathrm{m}$. 


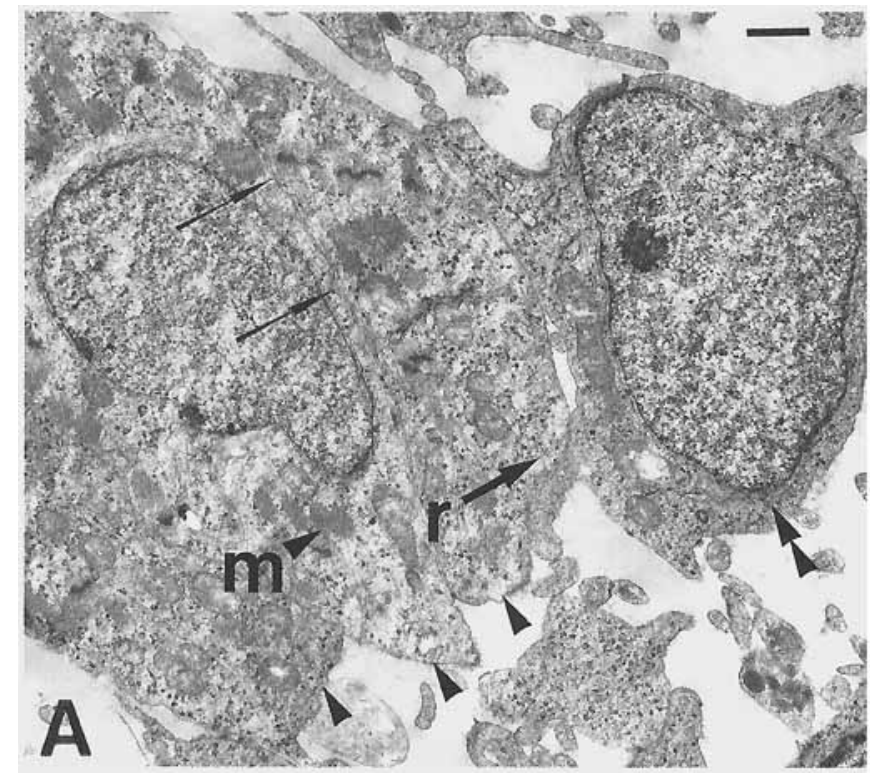

Fig. 4. Cell types within developing muscles. A: Differentiating muscle cells (arrowheads) in a stage 29 embryo were characterized by myofilaments (m), numerous ribosomal clusters ( $r$ ), and a smooth profile. These cells were often closely apposed to others over much of their surfaces (arrows). Cells with a similar electron density (double arrowheads) also had a smooth profile but were devoid of myofilaments and

rounded by a thin layer of electron-dense cytoplasm (Fig. 4B).

The organization of these cell types is very similar within the myogenic zones at all the phases examined. The cells are typically organized as clusters of 3 to 5 closely apposed cells that correspond to the primary myotube clusters that have been described at the lightmicroscopic level (see McLennan, 1983). The clusters are separated from each other by extracellular space that is laced with filopodia. At least one muscle cell is always present within each cluster; this cell is often centrally located and is likely to be a primary myotube (Fig. 5A). The clusters are morphologically similar throughout the proximal-distal extent of each muscle anlage during any particular embryonic stage, and they do not obviously correlate in size or position with any phase of cleavage. The clusters gradually become more distinct within each muscle and by stage 30 form units with smoother profiles and with fewer cellular processes extending between groups (see also Fig. 6). In addition, clusters are not obviously concentrated within the regions where motor nerves enter the muscles. Our morphometric analysis of each muscle sampled at each phase of cleavage detected no significant differences in the number of muscle cells, the number of mesenchyme cells, or the percentage of extracellular space in each unit area. Therefore, during the embryonic stages we examined, the muscles themselves were not undergoing significant changes in the features we measured.

\section{Uncleaved Phase: Initial Alterations Within the Incipient Cleavage Zone}

The distribution of cell populations within the incipient cleavage zone is remarkably similar to that within

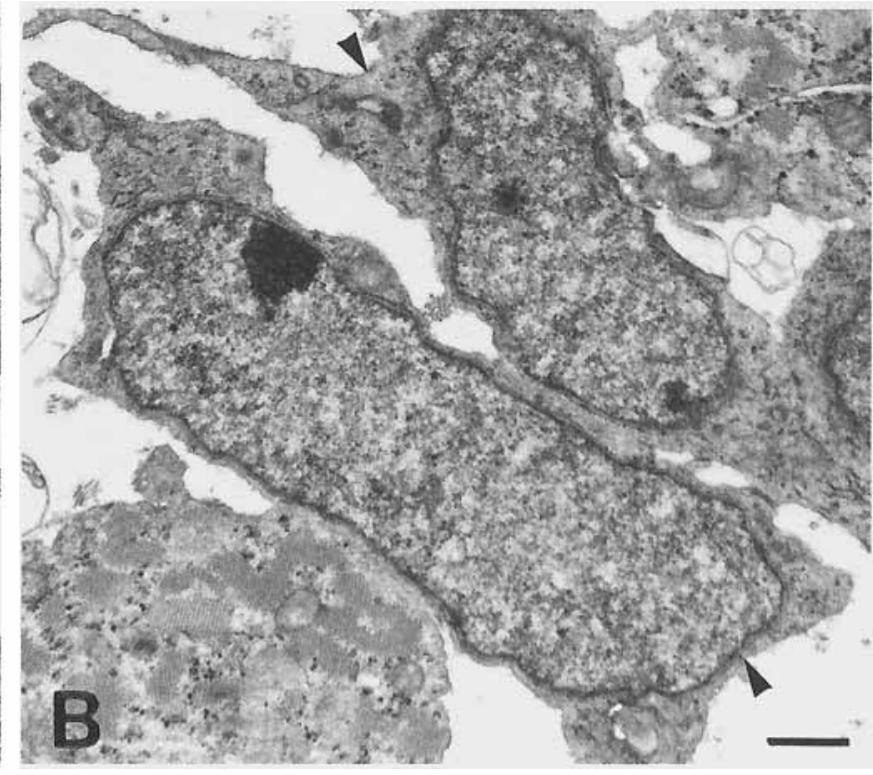

had a thinner layer of cytoplasm and a large nucleus. Such cells are likely to be developing myoblasts and were treated as muscle cells in the morphometric analysis. B: Mesenchyme cells (arrowheads) within the muscle displayed an irregular and elongated shape and an oval nucleus surrounded by a thin layer of electron-dense cytoplasm. Stage 28.5 embryo. Bars $=1 \mu \mathrm{m}$.

the muscle during the uncleaved phase; both muscle cells and mesenchyme are present. It was particularly interesting to find muscle cells in the cleavage zone, since one hypothesis has suggested (Noakes et al., 1986) that the incipient cleavage zone is defined by regions where muscle cells do not differentiate. An independent marker for muscle cell differentiation confirmed that muscle cells had differentiated within the incipient cleavage zone before overt cleavage. As shown in Figure 7, monoclonal antibody MF 20, which binds to sarcomere myosin (Bader et al., 1982; Shimizu et al., 1985), labels cells within the incipient cleavage zone. In addition, morphometric analysis confirmed that the numbers of muscle cells per unit area were not significantly different in the incipient cleavage zone and in the adjacent muscle. These observations suggest that muscle separation is not due to the failure of myotubes to differentiate in the presumptive cleavage zone.

Muscle proper and incipient cleavage zone are not, however, identical in all respects. The first difference revealed by the electron micrographs is an increase in extracellular space within the incipient cleavage zone. Despite the relatively homogeneous appearance of this entire region when examined qualitatively at the lightmicroscopic level, paired t-tests showed a significant increase in the percent extracellular space in the incipient cleavage zone in comparison with the muscles $(P<0.05 ;$ Fig. 8 shows all values that met our criterion for significance). An increase in extracellular space is thus a very early event in the establishment of the cleavage zone.

A second, qualitative difference is in the organization of the myotube clusters. The cells within myotube 

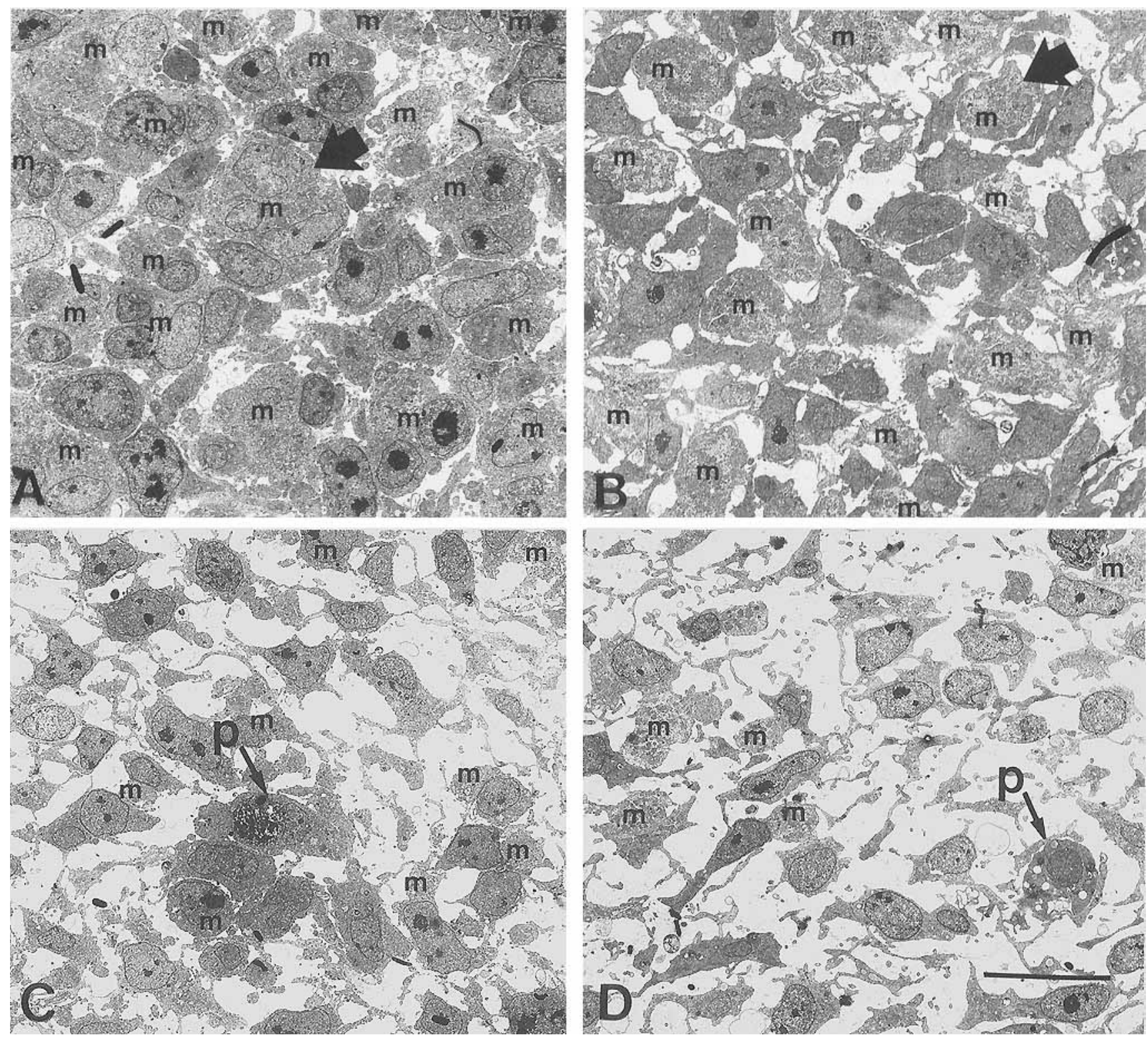

Fig. 5. Comparison of muscle and cleavage zone during cleavage. A: Muscle. Cells within muscles are typically organized as clusters (arrow) of 3 to 5 closely apposed cells, containing at least one muscle cell $(\mathrm{m})$. The clusters are morphologically similar within muscle at all phases of cleavage; the number of cells per cluster and the close association among cells does not obviously alter. B: Cleavage zone during the uncleaved phase. One of the earliest differences between muscle and cleavage zone is an apparent dispersal of myotube clusters (arrow) within the incipient cleavage zone. Muscle cells and clusters are more loosely associated with neighboring cells, and the contacts between cells are less extensive. In addition, fewer cells comprise a cluster, further suggesting a loss of cell-cell associations. C: Cleavage zone during the cleaving phase. Two striking characteristics distin-

clusters in the incipient cleavage zone make fewer and less extensive contacts with one another and are more loosely packed in comparison with myotube clusters in adjacent muscle (see arrows in Fig. 5A,B). This alteration in the association of cells may contribute substantially to the perception that extracellular space is

guish this region from that in the previous phase: the number of muscle cells declines and phagocytic cells (p) are commonly seen. Muscle cells within the cleavage zone appear to be selectively removed by phagocytes. In addition, while some myotube clusters can still be identified in the cleavage zone during this phase, the cells tend to be more isolated; and extensive cell-cell contact is less common than during the previous phase. D: Cleavage zone during the cleaved phase. The cleavage zone is now populated almost entirely by mesenchyme cells; few muscle cells remain and these are still subject to removal by phagocytes. In addition, the remaining mesenchyme cells are more stellate and resemble cells in the loose connective tissue in regions surrounding muscles. Abundant, isolated filopodia are seen throughout the increased extracellular space. Bar $=10 \mu \mathrm{m}$

increasing and cell density is decreasing within this cellular population. Instead of forming dense clusters separated by space, the cells are more evenly spread over the same area. Since the cells in the clusters appear to spread farther apart as cleavage progresses (see below), this initial loss of cell interactions is likely to 

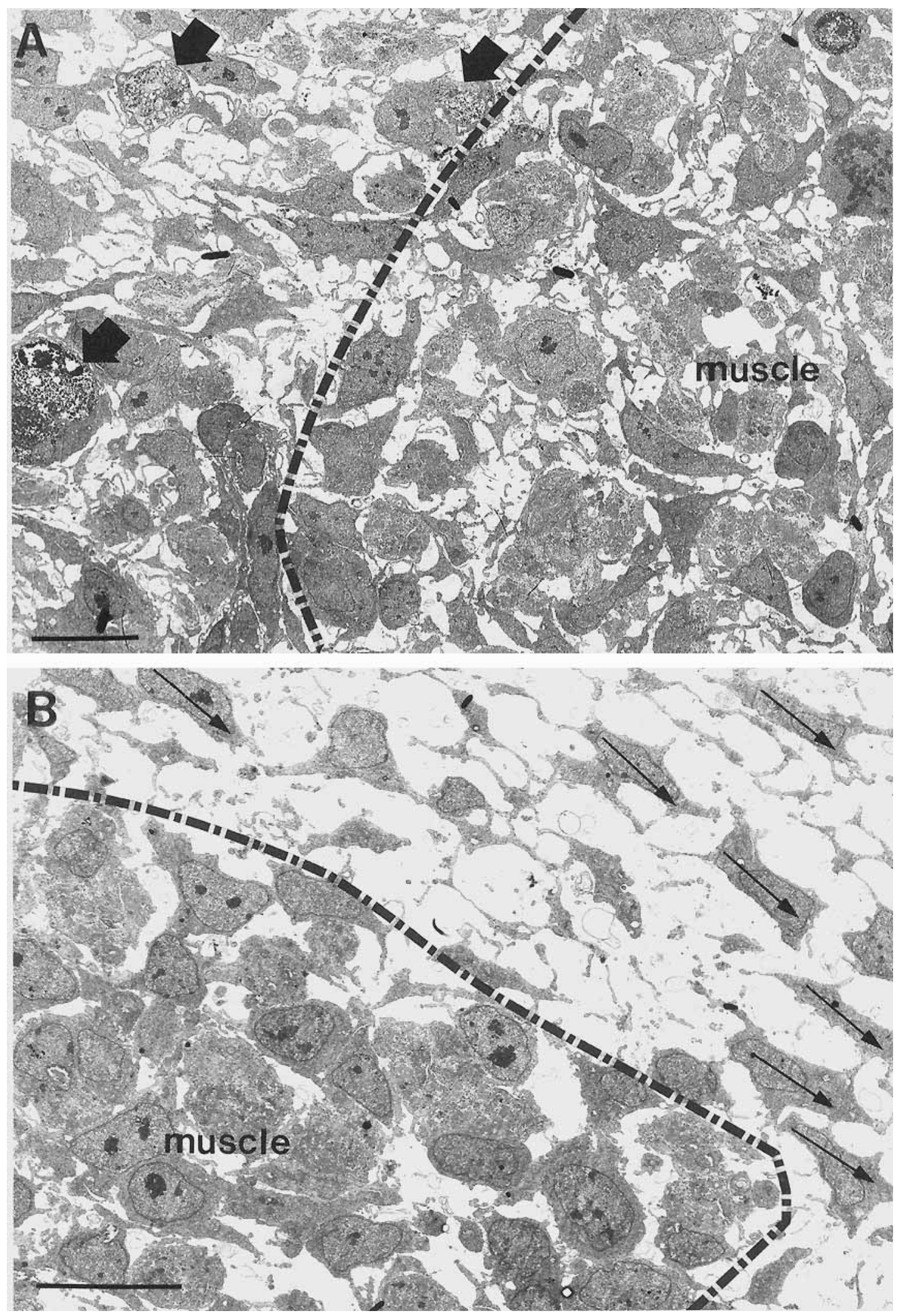

Fig. 6. Interface between muscle and surrounding mesenchyme. A: Phagocytes (arrows) are common at the edges of muscles as well as within the cleavage zone (see Fig. 7). Stage 28 embryo. B: Mesenchyme cells exterior to muscle align with their long axes (arrows) and filopodia paraliel with the surface of the muscle. Stage 29 embryo. Bars $=10 \mu \mathrm{m}$. 


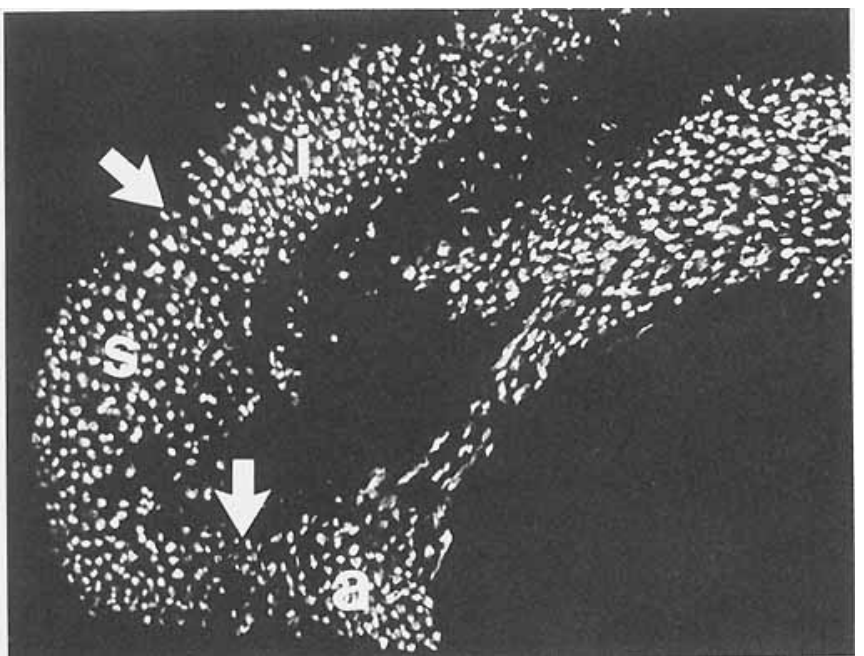

Fig. 7. Distribution of muscle cells as shown by immunocytochemistry. The distribution of differentiated muscle cells was confirmed during cleavage phases using an independent marker of muscle cell differentiation, monoclonal antibody MF 20 to sarcomere myosin. Arrows demarcate the incipient cleavage zones between the sartorius (s) and iliotibialis (i) and between the sartorius and ambiens (a). Differentiated muscle cells are clearly present in these developing cleavage zones.

reflcct a gradual dispersal of cells within the clusters. A similar loose association of cells within myotube clusters is typical of the transition arca between muscle and the connective tissue exterior to the muscles.

\section{Cleaving Phase: Removal of Muscle Cells by Specific Phagocytosis}

The initial differences that characterize the cleavage zone at the uncleaved phase become more pronounced in the cleaving phase. Myotube clusters are now much more loosely packed and the component cells are obviously less closely associated with one another (Fig. 5C). The percent extracellular space is again significantly higher than in adjacent muscle $(P<0.003$; Fig. 8$)$ but is not significantly different from that in the cleavage zone in the uncleaved phase; the extracellular space gradually increases within the cleavage zone as cleavage progresses.

The ultrastructural level of analysis also reveals striking new characteristics. The first is a diminution in the number of cells per unit area in the cleavage zone $(P<0.001)$. The decrease in total cell number during the cleaving phase is due solely to the loss of muscle cells from the cleavage zone. The number of mesenchyme cells is not significantly different from that in adjacent muscle or in the uncleaved regions of the cleavage zone. However, the number of muscle cells is significantly lower $(P<0.0001)$ in the cleavage zone than in adjacent muscle during the cleavage phase. The most active phase of cleavage is characterized, therefore, by the localized disappearance of differentiated muscle cells from the cleavage zone.

The second difference is the appearance of phagocytic cells. Phagocytes are particularly plentiful in the regions of active cleavage but are seldom seen within muscle. Some of these phagocytic cells contain masses of cellular debris and have ultrastructural characteristics typical of macrophages, including numerous, stringy processes (Fig. 9A; see also Fig. 6). In other cases, cells that appeared to be in the act of phagocytosis are indistinguishable from mesenchyme cells. For example, in Figure 9B, two muscle cells in the center of the cleavage zone appear to be engulfed by a neighboring mesenchyme cell. At a higher magnification (Fig. 9C), the myofilaments look disorganized as if the cells were either dying or being destroyed by the phagocytic cell. When engulfed, some signs of degenerative change such as this are generally detectable in the muscle cells. This feature distinguished a phagocytic interaction from the similar close association between muscle and mesenchyme cells in the myotube clusters within the muscles.

We emphasize that the phagocytosis is highly cellspecific. The phagocytes engulf only muscle cells; in no case did we see engulfment of other cell types. Whenever cellular structure could still be made out in engulfed cells, characteristics of muscle such as myofilaments could be identified. Muscle cells become isolated as they lose cell-cell contacts with other cells in the dispersing myotube clusters. The isolation itself may predispose the muscle cells to phagocytosis or it may indicate a prior alteration in their properties that renders them susceptible to phagocytic removal. Although these muscle cells may be marked in some way for engulfment by early degenerative changes, such changes were never detected ultrastructurally before engulfment. Muscle cells within the cleavage zone appear to be selectively phagocytized and removed.

A number of experiments can be envisioned to determine whether muscle cells in the cleavage zone are dying or whether they are being killed by the phagocytes. For example, cell death can be prevented in embryos exposed to a low dose of 5-bromodeoxy-uridine just before and during the time of muscle separation. If muscle cleavage proceeds abnormally, it is likely that muscle cells in normal embryos die before they are recognized and engulfed by phagocytes. If cleavage proceeds normally, it is likely that either phagocytes are killing isolated, healthy muscle cells, or the removal of muscle cells by phagocytes does not play a significant role in the separation process. In an alternative experiment, phagocytes can be prevented from entering the limb. If muscle cells within the cleavage zone die anyway, then it is likely that phagocytes are recognizing and removing dying muscle cells during normal development. These are only a few of the possible results and experiments that could answer the question of whether muscle cells in the cleavage zone die or whether they are killed by phagocytes.

Phagocytosis parallels the disappearance of muscle cells, and phagocytes are the one cell type that distinguishes cleavage zones from adjacent myogenic regions. Moreover, phagocytes engulf only differentiating myotubes in this location. We conclude, therefore, that the selective removal of muscle cells by phagocytosis plays an important role in the establishment of the cleavage zone. Since we also see phagocytes around the outer borders of muscle, in the transition regions that share with the cleavage zone characteristics such as more loosely packed myotube clusters and abundant, stellate mesenchyme cells (Fig. 6), the process of 


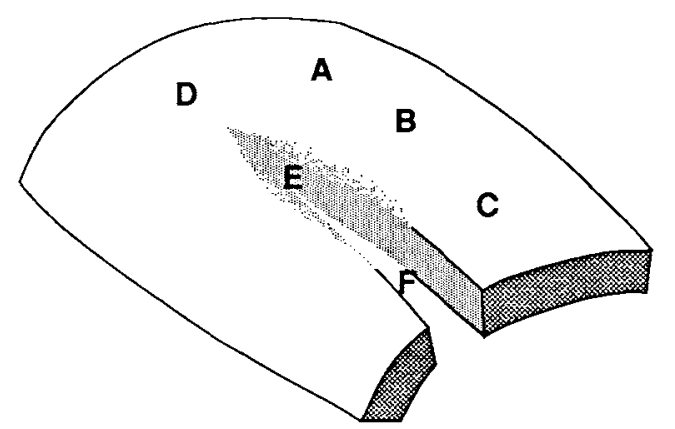

MEANS N SD SIG

\section{A. Percent Extracellular Space} in muscle

A: 41.29

A: 39.58

B: 37.71

C: 38.82

C: 38.82

in cleavage zone

D: 50.38

D: 48.58

E: 51.13

F: 63.03

E: 50.50

F: 63.46

cleavage

E: 50.96

F: 64.03

one vs muscle

A: 40.73

B: 37.71

C: 37.63

\section{Number of Muscle Cells}

in muscle

A: 9.43

A: 9.17

B: 13.67

B: 13.43

C: 11.00

C: 11.00

in cleavage zone

D: 7.67

D: 8.80

E: 4.83

E: 4.40

$\mathrm{F}: 1.50$

$\mathrm{F}: 1.60$

cleavage

E: 4.71

F: 1.50

$\begin{array}{ll}11.9 & .457 \\ 7.75 & .818 \\ 10.2 & .894 \\ & \\ 6.79 & .798 \\ 4.32 & .007 \\ 7.49 & .018 \\ & \\ 8.63 & .041 \\ 7.04 & .003 \\ 6.41 & .004\end{array}$

\section{$\begin{array}{llll}\text { MEANS } & N & S D & \text { SIG }\end{array}$}

\section{B. Number of Cells}

in muscle

A: 22.71 B: $25.14 \quad 7 \quad 8.42 \quad .475$

A: 21.33 C: $23.33 \quad 6 \quad 6.42 \quad .490$

B: 24.17 C: $23.33 \quad 6 \quad 9.95 \quad .846$

in cleavage zone

D: 7.33 E: $16.33 \quad 6 \quad 5.59 \quad 679$

D: $18.00 \mathrm{~F}: 18.25 \quad 4 \quad 5.32 \quad .931$

E: $15.60 \mathrm{~F}: 18.40 \quad 5 \quad 4.66 \quad .250$

cleavage zone vs muscle

D: $17.33 \mathrm{~A}: 22.33 \quad 6 \quad 10.86 \quad .311$

E: 15.57 B: $25.14 \quad 7 \quad 2.94 \quad .000$

F: 17.50 C: $23.00 \quad 4 \quad 7.05 \quad .217$

\section{Number of Mesenchyme Cells}

in muscle

A: 13.29 B: $11.71 \quad 7 \quad 5.68 \quad .492$

A: 12.17 C: $12.33 \quad 6 \quad 4.83 \quad .936$

B: $10.50 \mathrm{C}: 12.33 \quad 6 \quad 4.40 \quad .354$

in cleavage zone

D: 9.67 E: $11.50 \quad 6 \quad 5.49 \quad .451$

D: $10.00 \mathrm{~F}: 16.75 \quad 4 \quad 4.50 \quad .050$

E: $11.20 \mathrm{~F}: 16.80 \quad 5 \quad 4.56 \quad .052$

cleavage zone vs muscle

$\begin{array}{lllll}\text { D: } 9.67 & \text { A: } 13.00 & 6 & 7.66 & .335 \\ \text { E: } 10.86 & \text { B: } 11.71 & 7 & 2.34 & .370 \\ \text { F: } 16.00 & \text { C: } 11.50 & 4 & 5.80 & .219\end{array}$

Fig. 8. Paired t-tests for differences in extracellular space and distributions of cells within the emerging cleavage zone and muscles from seven embryos. Data were obtained from 2 or 3 phases of cleavage for each embryo, and data from the same embryo were paired to eliminate variance between chickens. The letters correspond to the

locations on the diagram from which the 20- $\mu \mathrm{m}$ samples were taken. A-C are within muscle; and D-F are within the cleavage zone. Means for each phase are indicated on the left under each heading. N, number; SD, standard deviation; SIG, level of significance at $P<0.05$.

phagocytosis may be generally associated with establishing muscle integrity by selectively removing isolated muscle cells.

\section{Cleaved Phase: Maturation of the Space Between Muscles}

During the cleaved phase, the cleavage zone has matured to form the space between muscles and resembles in many respects the region of loose connective tissue that lies exterior to muscles. Few muscle cells are present. The number of muscle cells is significantly lower in the cleavage zone at this phase than in adja- cent muscle $(P<0.04)$ or in the cleavage zone of the previous phase $(P<0.02)$. Those muscle cells that are seen are more likely to be associated with phagocytes than organized into clusters. After cleavage is complete at stage 31 , muscle cells cannot be found between muscles.

The cleavage zone is increasingly populated by mesenchyme cells that are separated from one another and evenly spaced (Fig. 5D). Despite the selective loss of muscle cells, the number of cells in the cleavage zone has increased and is no longer significantly different 

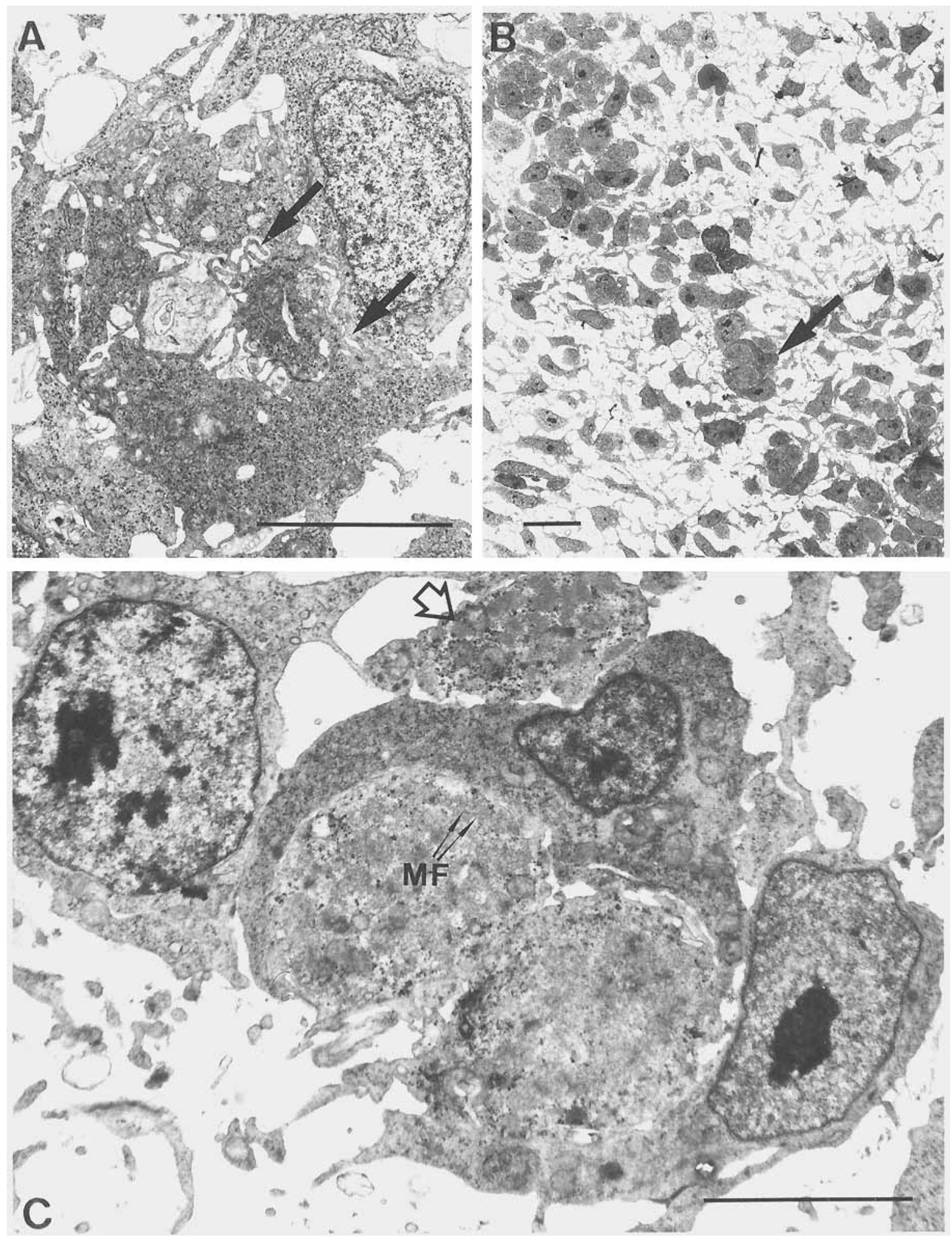

Fig. 9. Phagocytosis of muscle cells within the cleavage zone. A: Phagocytic cells are common within the cleavage zone during cleaving and cleaved phases. These cells often have ultrastructural characteristics typical of macrophages, including numerous stringy processes (arrows). B: Other phagocytic cells were indistinguishable from mesenchyme. For instance, the mesenchyme cell in the center of the cleavage zone (arrow) appears to be engulfing isolated muscle cells. $C$; When these cells are viewed at higher magnification, it is clear that the engulfed cells are muscle cells. In all engulfed cells in which cytoplasmic contents were still identifiable, we found myofilaments (MF), suggesting that phagocytosis is cell-specific. In addition, signs of degeneration were detectable in all engulfed cells. For instance, the dispersed array of myofilaments (arrows) in these cells contrasts with the tight, regular pattern seen in a normal muscle cell (clear arrow). All from a stage 28.5 embryo. Bars in $A, C=5 \mu \mathrm{m}$; in $B=10 \mu \mathrm{m}$. 
from that in the adjacent muscle. The restoration of cell density is apparently due to a compensatory increase in the number of mesenchyme cells, which is significantly greater $(P<0.05)$ within the cleavage zone in the cleaved than in the cleaving phase. It is not clear whether the increase in mesenchyme cells is due to a modest influx of an exterior population or to a local rise in mitotic rate. As discussed below, we do not see morphological signs of migration. In addition, while we could detect occasional mitotic figures in cleavage zones, they were too few in number for a statistical analysis.

The morphology of the mesenchyme cells in the cleavage zone gradually changes during cleavage. By the cleaved phase, mesenchyme cells are much more spatially complex in the cleavage zone than in adjacent muscle and are more similar to the highly stellate mesenchyme within the loose connective tissue surrounding muscle than they are to their counterparts within muscle (see Figs. 5,6). A 2-way analysis of variance established that mesenchyme cells had a significantly larger number of cell processes than muscle cells regardless of cleavage phase or location $\left(F_{(1,5)}=34.11\right.$; $P<.002)$. Furthermore, a paired t-test showed that the mesenchyme cells within the cleaved zone have significantly more cell processes than their counterparts in adjacent muscle during the cleaved phase $(P<0.01)$, showing a significant alteration in cellular morphology. Moreover, the number of isolated filopodia (processes that could not be traced to cell bodies) is significantly larger $(P<0.03)$ between cleaved muscles, indicating the greater abundance of cell processes in this region. Mesenchyme cells within the cleavage zone thus become more stellate as cleavage proceeds. The change in the shape of these mesenchyme cells is likely to indicate their differentiation to form loose connective tissue.

Stellate mesenchyme cells gradually intermix with the cells composing the muscles at the interface between the muscles proper and the mesenchyme of the limb, forming a transition area rather than a sharp boundary between the two tissues. The mesenchyme cells within the cleaved zone between muscles are more spatially complex, and the extension of abundant cellular processes in three dimensions strengthens the impression of increased extracellular space and decreased density of cells that are so distinctive of muscle separation at the light microscopic level.

The percent of extracellular space continues to increase in the cleavage zone and is significantly greater than in adjacent muscle $(P<0.004)$ or in the cleavage zone at the cleaving phase $(P<0.02)$. However, the number of cells within a unit area of the cleavage zone is not significantly different from that in adjacent muscle either before or after cleavage. A change in population distribution within the cleavage zone may help to explain how the extracellular space increases without an associated, statistically significant decrease in the number of cells. The total cellular area in the cleavage zone is significantly less than in muscle during uncleaved $(P<.05)$, cleaving $(P<.001)$, and cleaved $(P<.01)$ phases. In addition, the increased number of cell processes on mesenchyme cells extend the actual area occupied by these cells without completely filling the extracellular space with cytoplasmic area. There- fore, the increase in extracellular space without a concomitant decrease in cell number within the cleavage zone is at least partially explicable in terms of a replacement of large muscle cells by smaller and more stellate mesenchyme cells. Similar changes in cell shape and cell-cell contact with only modest changes in cell number are associated with an apparent increase in cell density during the condensation of the premuscle masses and limb cartilages (Gould et al., 1972, 1974; Searls et al., 1972; Hilfer et al., 1973; but see Thorogood and Hinchliffe, 1975).

\section{The Cleavage Zone: A Wedge of Intruding Cells or an Area of Cell Transformation?}

The above observations are consistent with transitions of a population in situ to form the cleavage zone, but do not necessarily rule out an alternative, i.e., that cleavage represents the massive intrusion of an outside population. These two mechanisms, however, make different predictions concerning the distribution of the condensed regions that represent the muscle primordia before and after cleavage. If some of the condensed population alters in situ to form the more loosely packed cleavage zone, then the total cross-sectional area of the condensed region that represents both muscle primordia should decrease. Alternatively, if the condensations are separated by an invading population, the regions of condensation representing each muscle anlagen should not decrease in size but should be pushed apart.

To address this issue, we compared the overall dimensions of the muscles in cross section before and after cleavage. As shown in Figure 10, camera-lucida tracings of the total cross-sectional area of the sartorius and iliotibialis muscles before (dark lines) and after (stippling) cleavage are essentially superimposable. If an exterior population the width of the cleavage zone had inserted itself between the muscles, we would have expected the total area encompassed by the two muscles and the intervening cleavage zone to increase. Instead, the total area has remained the same. In addition, the proportion of the total cross-sectional area that is occupied by condensed cells has decreased after cleavage; a central region of less condensed cells is now present in the center of the condensation, as though a population has emerged in situ to form the cleavage zone. These observations support the notion that the cleavage zone arises through transitions in the resident population.

We specifically looked for and did not find cells that were aligned in a manner that would lead them into or out of the cleavage zone in either transverse or longitudinal planes of section. In fact, the majority of the mesenchyme cells within the cleavage zone are stellate, a morphology that is not usually associated with active cell migration (Fig. 5C,D). The aligned populations we did observe in transverse sections do not correlate in space or time with the process of cleavage. For instance, mesenchyme cells between the ectoderm and the muscle are commonly aligned parallel with the dorsal edge of the muscles, but this population was seen only in regions where muscle had already cleaved (Fig. 6 ). These cells may be precursors of the epimyseum that surrounds each muscle later in development. Shellswell et al. (1980) also concluded, based on immu- 


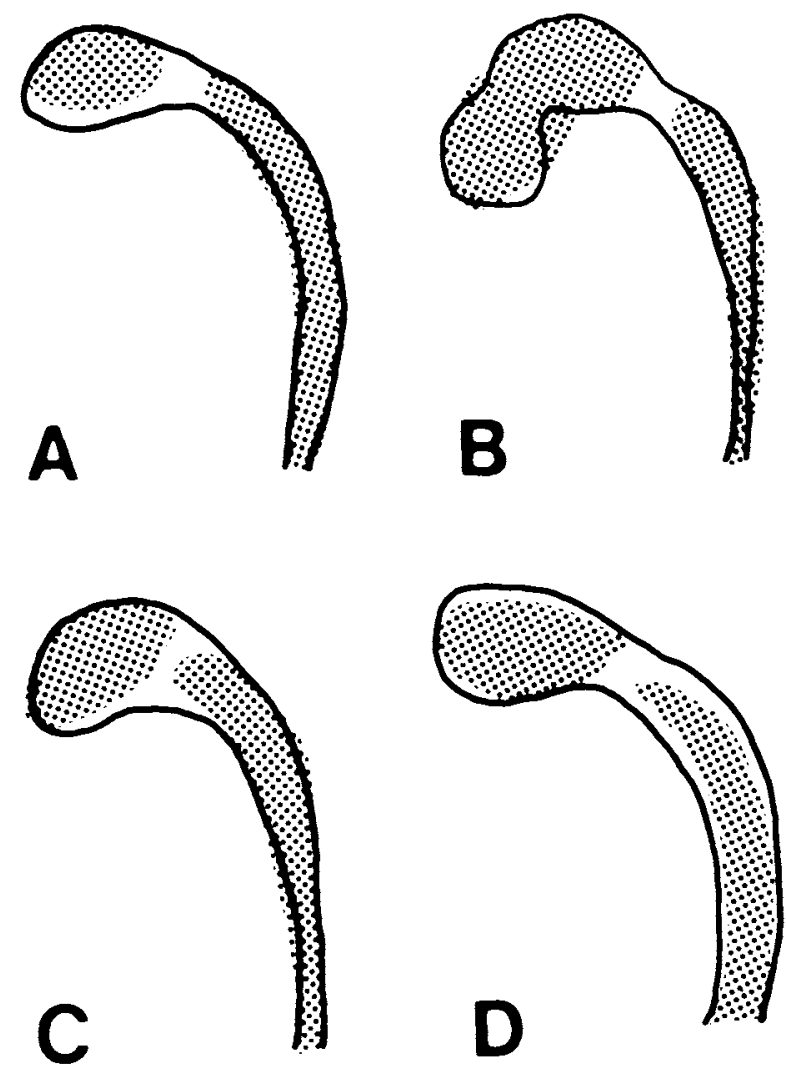

Fig. 10. Comparison of cross-sectional ared before and after cleavage. A, Stage 27.5; B, stage 28; C, stage 29; D, stage 30. Cameralucida tracings of the iliotibialis and sartorius muscles before (dark outlines) and after (stippled areas) cleavage have been superimposed and show that there is little or no increase in the total area occupied by the muscles and cleavage zone after cleavage is completed. This similarity in cross-sectional area before and after cleavage does not support a mechanism in which a large influx of an exterior population separates the two muscle anlagen. Instead, the region of decreased cell density appears to emerge in situ. In addition, note the more extensive tissue shrinkage in tissue that had been fixed in Bouin's and Carnoy's solutions and embedded in paraffin $(A, B)$ in comparison to tissue fixed in glutaraldehyde and embedded in plastic $(C, D)$. Despite these differences, similar patterns of condensation are apparent. The similarity suggests that local differences in cell density are not a preparation artifact, as has been suggested for other systems (see Thorogood and Hinchliffe, 1975).

nohistochemistry, that this tissue develops too late to play a causal role in muscle cleavage. These observations cannot rule out a modest role for active cell $\mathrm{mi}$ gration during cleavage, but they do not support a model in which there is a massive influx of cells.

Two additional populations, blood vessels and nerves, may be considered as invasive populations, but their distribution does not correlate with muscle separation patterns. Blood vessels were abundant within the surrounding presumptive connective tissue and in the cleavage zone and were slightly less abundant within muscle. However, there is no obvious correlation between the distribution of blood vessels and the separation of muscles. Likewise, the positions where nerves invaded muscle anlagen do not correlate with patterns of separation.

\section{Immunohistochemistry of the Distribution of Extracellular Matrix Components}

Increased extracellular space and transitions of cells to more stellate morphologies are commonly attributed to an increased incidence of or to a change in the composition or degree of hydration of the extracellular matrix (ECM; see Toole, 1972; Singley and Solursh, 1981). We looked for differential binding by four monoclonal antibodies to different ECM components along the progressing cleavage zone. If a particular epitope were to play an initiating role in cleavage, we would expect to detect it within the incipient cleavage zone, rather than after the process begins. We did not discover such a pattern of staining; it remains possible, however, that an epitope may be expressed in such a pattern but that the expression is at too low a level to be detected by light-microscopic analysis. Additional epitopes that were not recognized by the antibodies in this study may also be expressed in such a pattern. Another pattern of expression that would directly implicate an epitope in the process of cleavage is its expression only within the cleavage zone. We found no epitope that is characteristic of the cleavage zone alone with the monoclonal antibodies used in this study.

Instead, the labeling pattern of all epitopes examined is consistent with what would be expected from the distribution of muscle and mesenchyme cell populations during each phase of cleavage. In all cases the uncleaved portion of the cleavage zone labels similarly to muscle; the cleaved portion labels like the loose connective tissue exterior to muscle. Figure 11 shows the patlerns of labeling in the cleavage zone during the cleaving phase; in all cases the pattern is intermediate between that in muscle and that in connective tissue. For instance, muscle and femur label darkly and surrounding connective tissue labels lightly with antibody $2 \mathrm{~B} 6$ after treatment with chondroitinase $\mathrm{ABC}$, a treatment that is specific for the labeling of chondroitin4-sulfate and dermatan sulfate. Label within the cleavage zone is intermediate in intensity (Fig. 11A). A second pattern of labeling, seen with antibody CS-56 to chondroitin sulfate proteoglycan, is complementary in that connective tissue surrounding muscles labels more intensely than muscle. Immunoreactivity in the cleavage zone is intermediate in intensity during the cleaving phase, with some scattered, dark labeling like that in connective tissue (Fig. 11B). Two antibodies, 5D4 (to keratan sulfate) and 3B3 (to chondroitin6-sulfate), label neither muscle nor connective tissue and the cleavage zone is also unlabeled (Fig. 11C,D). These results suggest that ECM characteristic of connective tissue accumulates within the cleavage zone as cleavage proceeds.

\section{DISCUSSION \\ Summary of the Temporal-Spatial Alterations That Characterize Muscle Separation}

Muscle separation progresses in an orderly fashion along the proximal-distal axis and can be systematically sampled. Our analysis of three phases of cleavage thus allows us to infer the temporal sequence of events that characterize the emerging cleavage zone between muscles. The extracellular space increases; the cells within myotube clusters progressively lose their close 

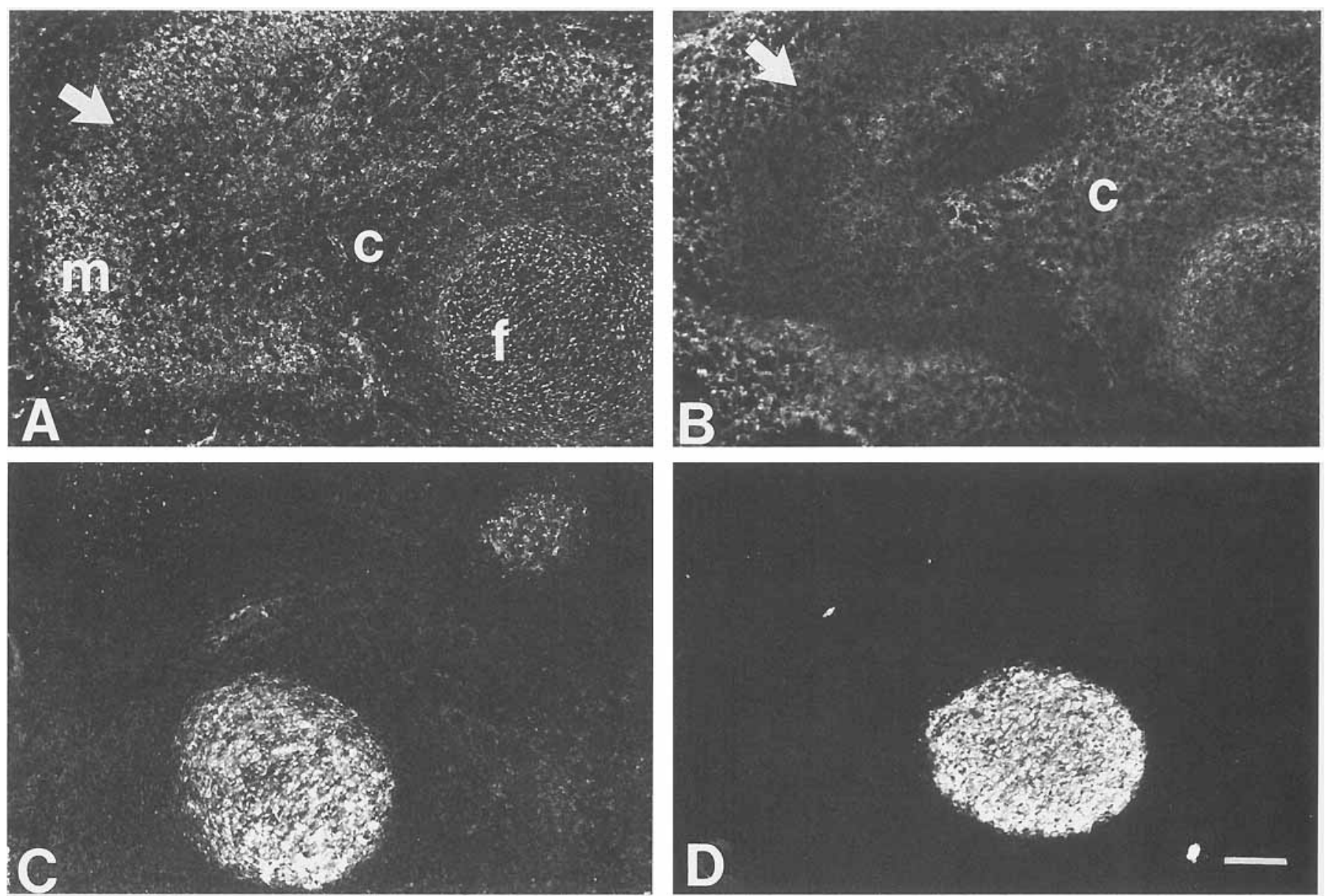

Fig. 11. Immunoreactivity of four monoclonal antibodies to ECM components during the cleaving phase. A: Monoclonal antibody 2B6, specific for chondroitin-4-sulfate and dermatan sulfate after digestion with chondroitinase $A B C$, strongly labels muscle (m) and femur (f) and weakly labels surrounding connective tissue (c). Label within the cleavage zone (arrow) is intermediate in that some cells label darkly and some lightly. B: A second labeling pattern, seen with antibody CS-56 to chondroitin sulfate proteoglycan, is complementary in that

cell-cell associations; the number of cells per unit area transiently decreases during the cleaving phase due to the preferential loss and phagocytosis of muscle cells; and the mesenchyme cells gradually change their morphology to become more stellate, more evenly spaced, and, in the final phase of cleavage, more abundant. Similar changes appear to characterize the regions exterior to muscle. By the time the muscles have separated, the ECM within the cleavage zone differs in composition from that within muscle and is similar to that seen in the connective tissue exterior to the muscle in that chondroitin sulfate proteoglycan is present. Our characterization of these alterations provides a realistic baseline to address possible mechanisms of cleavage, which we discuss below.

\section{What is Responsible-Muscle or Mesenchyme?}

The convenient physical separation of the embryological sources of limb muscle and connective tissue (the somite and somatopleure respectively) has made it connective tissue surrounding muscles labels more intensely than muscle. Label in the cleavage zone (arrow) is intermediate during the cleaving phase with some scattered cells as darkly labeled as those in connective tissue. C,D: In a third pattern, seen with antibody 5D4 to keratan sulfate (C) and 3B3 to chondroitin-6-sulfate (D), only developing cartilage is darkly labeled. Neither muscle nor connective tissue are labeled and immunoreactivity is not detectable within the cleavage zone. Bar $=100 \mu \mathrm{m}$.

possible to show that the pattern of muscle separation is established early, and that this pattern is inherent in the connective tissue precursors rather than in the presumptive myoblasts (Christ et al., 1977; Dienstman et al., 1974; Chevallier and Kieny, 1982; Noden, 1983; Mauger et al., 1983; Lance-Jones, 1988; reviewed by Kieny, 1977). Myogenic precursors within the somite are not determined to form particular muscles. However, when the anterior-posterior axis of the somatopleure is rotated opposite the incipient anterior hindlimb, the muscles within the corresponding portion of the limb develop in reversed anterior-posterior order. These results show that the embryonic source of the connective tissue determines the eventual pattern of muscle separation.

Nevertheless, the developing connective tissue may not be the most proximate cause of the physical separation of muscles. An alternative manner in which this tissue may dictate the muscle pattern is by expressing a three-dimensional network of positional information 
in the limb (possibly based on expression of retinoic acid and its receptor; see Thaller and Eichele, 1987) that affects the differentiation pattern or properties of other cell types. There is in fact only one report that would lead us to believe that muscle is completely at the mercy of the connective tissue in muscle patterning and could, in effect, be dispensed with. Lanser and Fallon (1987) report that the shape of a muscle may be established within the connective tissue in the absence of muscle cells. This intriguing observation cannot at this stage be conclusive since muscle cells may have been present earlier and then degenerated before they were detected, and we still must consider how either population could bring about cleavage. In the interests of simplicity, we emphasize in the discussion below how a single developmental event could initiate all the events that characterize cleavage in each of several models.

\section{Models in Which Site-Specific Differences in Muscle Cells Initiate and Establish Separation}

In this section, we discuss models in which the process of cleavage is initiated by a programmed difference in the myogenic cells that lie along the incipient cleavage zone. In the first model, muscle cells are suggested to be programmed to die within the cleavage zone. Morphogenetic cell death is a common feature of several systems in which a spatially restricted population becomes determined to die and does so even if removed from its normal environment (see review by Saunders, 1966). For example, degenerative changes within myotubes in the developing human hand have been detected using histochemistry (Grim, 1978). In our ultrastructural analysis, we did not detect degenerative changes in muscle cells before phagocytosis, but such changes could be present and detected by phagocytes. Expression of the "death" program would change muscle cell properties which in turn could stimulate the loss of associations between muscle and mesenchyme cells and mediate the subsequent recognition and removal of muscle cells by phagocytes. If this model is correct, then muscle cells removed from incipient cleavage zones should die and do so on schedule.

In a second model, the effect of positional information is to inhibit muscle cell differentiation within the cleavage zone, which in turn is the proximate cause of muscle separation (see also Shellswell and Wolpert, 1977). This model is in accord with reported temporal differences in the pattern of initial differentiation. The first myotubes appear to differentiate in nucleation sites within the limb that have been suggested to correspond to individual muscle anlagen well before any signs of overt cleavage (Noakes et al., 1986; see also Tanaka and Landmesser, 1986). Muscle cell immaturity might also be reflected by the looser cell packing within myotube clusters in the incipient cleavage zone. However, we establish here that the position-dependent differentiation of myotubes does not explain cleavage in the most simple and straightforward way: myotubes do not fail to initiate differentiation within the cleavage zone and in fact do so at a density similar to that seen in muscle at all the embryonic stages studied. These results disprove the simple hypothesis that muscles cleave where they do because muscle cells never differentiate between muscle anlagen.
The above hypothesis can be modified to accommodate our results: muscle cells within the cleavage zone may be unable to proceed past a particular stage in differentiation, become moribund and subject to phagocytic removal. One distinguishing feature of muscle cell differentiation is the expression of fiber-type specific molecules. Some of the first of these molecules appear to be expressed coincident with or shortly after cleavage (Sweeny et al., 1989). It would be interesting to determine whether muscle cells in the cleavage zone do or do not express these molecules before being phagocytosed.

A third model in which cell adhesivity might decrease in the cleavage zone was proposed by Shellswell and Wolpert (1977). As originally stated, the decreased adhesivity would result in separation owing to a process of sorting out in the manner first described by Steinberg (1970) or owing to a physicial shearing along the region of reduced adhesivity. The fact that myotube clusters disperse is consistent with a lessening of cell adhesivity and suggests that lowered adhesivity is in fact a characteristic of cells within the cleavage zone. The decreased adhesivity could be a result of changes in the differentiation program of muscle in the cleavage zone; it could, for instance, be a result of a morphogenetic death program or of an inhibition of further differentiation. We find, however, no evidence of sorting out or of a shearing of the population along a region of decreased adhesion. If this model is to fit the parameters we have established, then the decreased adhesion must in some way target the muscle cells for phagocytosis.

In all of the models above, the primary impetus for cleavage is suggested to be a change in muscle cells that results in their removal from the cleavage zone. If so, then the concomitant alterations in the mesenchyme cells could be a consequence of the loss of interactions with muscle cells and need not be separately programmed. Mesenchyme cells deprived of the opportunity to associate with muscle cells may choose an alternative path of differentiation, becoming stellate cells of the loose intermuscular connective tissue, and expressing a corresponding pattern of ECM synthesis. Such binary differentiation choices have been suggested to be critically dependent upon timely cellular interactions in other systems (see, for example, Weston et al., 1988). A test of this proposition might combine or isolate muscle and mesenchyme in culture and determine whether their fates were dependent on interactions.

The loss of the muscle cell population could also explain the subsequent rise in mesenchyme cell number within the cleavage zone during the last phase of cleavage. The cell density within tissues appears to be controlled during development, as evidenced by the regulation of cell numbers following experimental deletion of a variety of populations during critical periods (see Mauger and Kieny, 1980, for an example of regulation in the limb). In addition, with the exception of the transient decrease in cell density during the cleaving phase, the number of cells per unit area is remarkably constant throughout muscle and associated tissue. It can be argued that there is a homeostatic mechanism to assure that characteristic cell densities are retained during development by control of mitotic and migra- 
tory processes, and that developmental "regulation" in response to manipulation reveals this compensatory mechanism. We propose that such a homeostatic mechanism may compensate for the deletion of muscle cells by a developmental mechanism, and that this deletion stimulates an increase in the remaining mesenchyme cell population until cell density is restored.

\section{Model in Which Cleavage Results From the Invasion of Mesenchyme Cells}

The possibility that muscles are separated by the incursion of a wedge of mesenchyme cells between the anlagen was initially identified as a possible mechanism by Shellswell and Wolpert (1977; see also Shellswell, 1977). This attractive hypothesis is consistent with the straightforward supposition that muscle is passive and mesenchyme active in muscle separation. In addition, Chiquet et al. (1981) showed by means of immunohistochemistry that fibronectin increases in the cleavage zone as muscles separate and suggested that an invasive population that synthesized fibronectin was migrating into the cleavage zone. While we also document an alteration in ECM within the progressing cleavage zone, we feel these molecular differences are also consistent with an alternative interpretation. A population that already resides within the incipient cleavage zone may synthesize a different set of extracellular molecules as cleavage progresses. The appearance of different molecules between muscles as they separate does not, therefore, provide direct evidence in favor of separation by an invading population.

Our morphological observations do not rule out the possibility that a small number of cells invades the cleavage zone, but neither do they provide strong support for a physical separation of muscle anlagen by an outside population. First, examination at the light-microscopic level shows that condensed myogenic regions do not retain their size and move apart during cleavage, but instead decrease in size as a less dense region emerges centrally between the two anlagen. This observation is consistent with the insertion of a wedge of cells only if this wedge caused the cells within muscle to further condense, which they do not, since the number of cells per unit area remains relatively constant within muscle at all phases. Second, we did not find aligned cells that would be consistent with a massive influx of an external population; however, we could not have detected a small influx, and cannot by this method rule out the possibility that migration makes an important if subtle contribution to cleavage. Third, the cell-cell associations and the mesenchyme morphology change progressively with cleavage, and it is particularly difficult to envision how an invading population could alter the cell-cell associations within populations that are already present in the cleavage zone. Finally, experimental manipulations suggest that there is little cell mixing and migration within the limb during the period of muscle separation. For instance, cells from quail or chick limbs implanted into a chick limb bud stay in place rather than invading or intermingling with surrounding populations (Tickle et al., 1978; Fisher and Solursh, 1979; Erickson et al., 1980). These experiments, however, did not specifically test the possibility that cells invade muscle masses. Very fine-grained fate mapping using homotypic trans- plantation of marked cells or vital dyes shortly before muscle cleavage commences could directly test the hypothesis that cells invade the cleavage zone. Our results, in the absence of such experimental evidence, cannot rule out this possibility, but they more directly support the notion that muscle separation is due to alterations in the cell populations within the muscle masses that lie along the incipient cleavage zone.

\section{Model in Which Cleavage Results From Site-Specific Differentiation of Connective Tissue}

We propose that mesenchyme cells in the cleavage zone are programmed to differentiate as loose connective tissue while those within muscle are programmed to form muscle-associated connective tissue. Consistent with this proposition is the similarity between the new ECM within the cleavage zone and that seen in loose connective tissue exterior to the muscles. Both sites display immunoreactivity for fibronectin (Chiquet et al., 1981) and, as we show, for chondroitin sulfate proteoglycan. Conversely, immunoreactivity for an epitope characteristic of muscle, chondroitin-4-sulfate, gradually decreases in the cleavage zone until it is similar to the low level in the loose connective tissue. It is thus plausible that the ECM composition changes as a result of mesenchyme cells differentiating and synthesizing components more typical of loose connective tissue. These ECM components may in turn directly stimulate the loss of cell contacts within myotube clusters. Certainly during cartilage development, ECM is commonly supposed to "push cells apart" (Gould et al., 1974). The increased stellate morphology of mesenchyme cells would also be a concomitant of their differentiation program. Many of the physical changes that characterize the cleavage zone could thus be natural consequences of a program of differentiation of the resident mesenchyme cells.

In this model, the death and removal of muscle cells within the cleavage zone is suggested to result from interactions with the differentiating mesenchyme cells. The most straightforward possibility is that differentiating connective tissue cells synthesize substances that inhibit the further maturation of muscle cells. This possibility is in accord with studies in culture suggesting that several ECM components inhibit differentiation of muscle cells (see Carrino and Caplan, 1986; Bischoff, 1978). For instance, while fibronectin may aid the migration of presumptive myoblasts and their early development (see Turner, 1986), it has also been suggested to inhibit muscle differentiation; fibronectin appears to delay the fusion of myoblasts in culture (Podleski et al., 1979). Furthermore, hyaluronic acid, which is often found in regions of loosely packed cells (see Toole, 1972), has been reported to inhibit the program of myogenesis (Kujawa and Tepperman, 1983; Kujawa et al., 1986). Further characterization of the ECM of the loose connective tissue and further examination of its effect on muscle fiber differentiation are clearly warranted. Although we think it less likely, it is also possible that the loss of mesenchymal contact either triggers a cell death program in the muscle cells, or removes some protection from phagocytosis. Phagocytosis of muscle fibers is characteristic of muscle remodeling during metamorphosis (Kerr et al., 1974), during muscle regeneration (Carlson, 1986), and in 
muscular dystrophies (e.g., Kirkeby and Mikkelsen, 1988) when normal cell-cell relationships are disrupted; however, there are likely to be factors other than cell-cell interactions contributing to the susceptibility of these more mature muscle fibers.

Any of the proposed scenarios in which the fate of muscle cells is dependent upon an interaction with mesenchyme more easily explain why muscle cells are phagocytosed at the outer edges of muscles where connective tissue is differentiating, as well as within the cleavage zones. Because of its simplicity and greater inclusiveness, we favor the model in which the programmed differentiation of mesenchyme cells in the cleavage zone initiates muscle cleavage. Since the morphogenetic pattern of the limb is supposedly set up by positional information contained within its tissues (Wolpert, 1969), an early role of positional information may be to instruct a pluripotent population of mesenchyme cells to form connective tissue along incipient cleavage zones or to assure that cells committed to this fate array themselves in the proper places. As these mesenchyme cells begin to differentiate in the cleavage zone and around the outer edges of muscles, they synthesize ECM or other substances that 1) stimulate the loss of cell contacts and the more even spacing among cells, 2) provide positive feedback for the continued differentiation of mesenchyme cells, and 3) provide negative feedback for local muscle cell differentiation that ultimately results in the specific recognition and phagocytic removal of these isolated muscle cells.

\section{ACKNOWLEDGMENTS}

We thank Kate Barald, Bruce Carlson, Steve Easter, and Rich Hume for critically reviewing the manuscript; David Bay for photographic assistance; and Jim Dennis for the antibodies and technical assistance. Merle Feldbaum at the Statistical Research Laboratory of the University of Michigan deserves special thanks for her aid in selecting and carrying out the appropriate statistical tests for the numerous groups of data.

S.S. thanks Dušan Baić for instruction in electron microscopy and Steve Easter for instruction in recording the morphometric data.

Funds for completion and presentation of this work were provided by NIH grant 02138 to K.W.T., NIH training grant T32 HD-07274-04, the Department of Biology, and the Rackham School of Graduate Studies.

\section{LITERATURE CITED}

Avnur, Z., and B. Geiger 1984 Immunocytochemical localization of native chondroitin-sulfate in tissues and cultured cells using specific monoclonal antibody. Cell, 38:811-822.

Bader, D., T. Masaki, and D.A. Fischman 1982 Immunochemical analysis of myosin heavy chain during avian myogenesis in vivo and in vitro. J. Cell Biol., 95:763-770.

Baumel, J.J., A.S. King, A.M. Lucas, J.E. Breazile, and H.E. Evans, eds. 1979 Nomina Anatomica Avium. Academic Press, London.

Bischoff, R. 1978 Myoblast fusion. In: Membrane Fusion, G. Poste and G.L. Nicolson, eds. Elsevier/North-Holland Biomedical Press, New York, pp. 127-179.

Caplan, A.I., and S. Koutroupas 1973 The control of muscle and cartilage development in the chick limb: the role of differential vascularization. J. Embryol. Exp. Morphol., 29:571-583.

Carey, E.J. 1920 Studies in the dynamics of histogenesis. I. Tension of differential growth as a stimulus to myogenesis. J. Gen. Physiol., $2: 357-372$.
Carlson, B.M. 1986 Regeneration of entire skeletal muscles. Fed. Proc., 45:1456-1460.

Carrino, D.A., and A.I. Caplan 1986 Proteoglycan synthesis during skeletal muscle development. In: Molecular Biology of Muscle Development, C. Emerson, ed. Alan R. Liss, Inc., New York, pp. 117-131.

Caterson, B., J.E. Christner, and J.R. Baker 1983 Identification of a monoclonal antibody that specifically recognizes corneal and skeletal keratan sulfate. J. Biol. Chem., 258:8848-8854.

Caterson, B., J.E. Christner, J.R. Baker, and J.R. Couchman 1985 Production and characterization of monoclonal antibodies directed against connective tissue proteoglycans. Fed. Proc., 44: $386-393$.

Chevallier, A., and M. Kieny 1982 On the role of the connective tissue in patterning of the chick limb musculature. Wilhelm Roux Arch., 191:277-280.

Chiquet, M., H.M. Eppenberger, and D.C. Turner 1981 Muscle morphogenesis: evidence for an organizing function of exogenous fibronectin. Dev. Biol., 88:220-235.

Christ, B., H.J. Jacob, and M. Jacob 1977 Experimental analysis of the origin of the wing musculature in avian embryos. Anat. Embryol. (Berl.), 150:171-186.

Cihák, R. 1972 Ontogenesis of the skeleton and intrinsic muscles of the human hand and foot. Adv. Anat. Embryol. Cell Biol., 46: $1-194$.

Dienstman, S.R., J. Biehl, S. Holtzer, and H. Holtzer 1974 Myogenic and chondrogenic lineages in developing limb buds grown in vitro. Dev. Biol., 39:83-95.

Erickson, C.A., K.W. Tosney, and J.A. Weston 1980 Analysis of migratory behavior of neural crest and fibroblastic cells in embryonic tissues. Dev. Biol., 77:142-156.

Fisher, M., and M. Solursh 1979 The influence of local environment on the organization of mesenchyme cells. J. Embryol. Exp. Morphol., 49:295-306.

Gould, R.P., A. Day, and L. Wolpert 1972 Mesenchymal condensation and cell contact in early morphogenesis of the chick limb. Exp. Cell Res., 72:325-336

Gould, R.P., L. Selwood, A. Day, and L. Wolpert 1974 The mechanism of cellular orientation during early cartilage formation in the chick limb and regenerating amphibian limb. Exp. Cell Res., 83: 287-296.

Grim, M. 1978 Acid phosphatase activity in normal and sarcolytic myotubes in muscle anlagen of the human hand. Histochemistry, $56: 307-316$.

Grim, M., and B.M. Carlson 1974 A comparison of morphogenesis of muscles of the forearm and hand during ontogenesis and regeneration in the axolotl (Ambystoma mexicanum). II. The development of muscular pattern in the embryonic and regenerating limb. A. Anat. Entwickl., 145:149-167.

Hamburger, V., and H.L. Hamilton 1951 A series of normal stages in the development of the chick embryo. J. Morphol., 88:49-92.

Harrison, R.G. 1905 An experimental study of the relation of the nervous system to the developing musculature in the embryo of the frog. Am. J. Anat., 3:197-220.

Hilfer, S.R., R.L. Searls, and V.G. Fonte 1973 An ultrastructural study of early myogenesis in the chick wing bud. Dev. Biol., 30 : $374-391$

Humason, G.L. 1972 Animal Tissue Techniques, 3rd ed. Freeman, San Francisco.

Jacob, H.J., and B. Christ 1980 On the formation of muscular pattern in the chick limb. In: Teratology of the Limbs, H.-J. Merker, H. Nau, and D. Neubert, eds. de Gruyter, Berlin, pp. 89-97.

Kerr, J.F.R., B. Harmon, and J. Searle 1974 An electron-microscope study of cell deletion in the anuran tadpole tail during spontaneous metamorphosis with special reference to apoptosis of striated muscle fibers. J. Cell Sci., 14:571-585.

Kieny, M. 1977 Proximo-distal pattern formation in avian limb development. In: Vertebrate Limb and Somite Morphogenesis, D.A Ede, M. Balls, and J. Hinchliffe, eds. Cambridge University Press, Cambridge, pp. 87-103.

Kirkeby, S., and H. Mikkelsen 1988 Macrophages and mast cells in dystrophic masseter muscle: a light and electron microscopic study. Br. J. Exp. Pathol., 69:597-603.

Kujawa, M.J., and K. Tepperman 1983 Culturing chick muscle cells on glycosaminoglycan substrates: attachment and differentiation. Dev. Biol., 99:277-286.

Kujawa, M.J., D.G. Pechak, M.Y. Fiszman, and A.I. Caplan 1986 Hyaluronic acid bonded to cell culture surfaces inhibits the program of myogenesis. Dev. Biol., 113:10-16.

Lance Jones, C. 1979 The morphogenesis of the thigh of the mouse 
with special reference to tetrapod muscle homologies. J. Morphol., 162:275-309.

Lance-Jones, C. 1988a The somitic level of origin of embryonic chick hindlimb muscles. Dev. Biol., 126:394-407.

Lance-Jones, C. $1988 \mathrm{~b}$ The effect of somite manipulation on the development of motoneuron projection patterns in the embryonic chick hindlimb. Dev. Biol., 126:408-419.

Lance-Jones, C. 1988c Motoneuron axon guidance: development of specific projections to two muscles in the embryonic chick limb. Brain Behav. Evol., 31:209-217.

Lanser, M.R., and J.F. Fallon 1987 Development of wing-bud-derived muscles in normal and Wingless chick embryos: a computer-assisted three-dimensional reconstruction study of muscle pattern formation in the absence of skeletal elements. Anat. Rec., 217: 61-78.

Mauger, A., and M. Kieny 1980 Migratory and organogenetic capacities of muscle cells in bird embryos. Wilhelm Roux Arch., 189: $123-134$.

Mauger, A., M. Kieny, I. Hedayat, and P.F. Goetinck 1983 Tissue interactions in the organization and maintenance of the muscle pattern in the chick Iimb. J. Embryol. Exp. Morphol., 76:199215.

McLennan, I.S. 1983 Neural dependence and independence of myotube production in chicken hindlimb muscles. Dev. Biol., 98:287294.

Noakes, P.G., A.W. Everett, and M.R. Bennett 1986 The growth of muscle nerves in relation to the formation of primary myotubes in the developing chick forelimb. J. Comp. Neurol., 248:245-256.

Noden, D.M. 1983 The role of the neural crest in patterning of avian cranial skeletal, connective, and muscle tissues. Dev. Biol., 96: 144-165.

Paterson, A.M. 1888 On the fate of the muscle-plate, and the development of the spinal nerves and limb plexuses in birds and mammals. Q. J. Microsc. Soc., 28:109-129.

Pautou, M.P., I. Hedayat, and M. Kieny 1982 The pattern of muscle development in the chick leg. Arch. Anat. Microsc. Morphol. Exp., 71:193-206.

Podleski, T.R., I. Greenberg, J. Schlessinger, and K.M. Yamada 1979 Fibronectin delays the fusion of L6 myoblasts. Exp. Cell Res., 122:317-326.

Romer, A.S. 1927 The development of the thigh musculature of the chick. J. Morphol., 43:437-385.

Romer, A.S. 1942 The development of tetrapod limb musculaturethe thigh of Lacerta. J. Morphol., 71:251-298.

Saunders, J.W., Jr. 1966 Death in embryonic systems. Science, 154: 604-612.

Schroeter, S., and K.W. Tosney 1987 Formation of individual muscles in the chick thigh. Soc. Neurosci. Abstr., 13:253.

Schroeter, S., and K.W. Tosney 1989 Timing and direction of muscle cleavage in the chick thigh. Soc. Neurosci. Abstr., 15:373.

Schroeter, S., and K.W. Tosney 1991 Spatial and temporal patterns of muscle cleavage in the chick thigh and their value as criteria for homology. Am. J. Anat. (this issue).

Searls, R.L., S.R. Hilfer, and S.M. Mirow 1972 An ultrastructural study of early chondrogenesis in the chick wing bud. Dev. Biol., 28:123-137.

Shellswell, G.B. 1977 The formation of discrete muscles from the chick wing dorsal and ventral muscle masses in the absence of nerves. J. Embryol. Exp. Morphol., 41:269-277.

Shellswell, G.B., and L. Wolpert 1977 The pattern of muscle and tendon development in the chick wing. In: Vertebrate Limb and
Somite Morphogenesis, D.A. Ede, J.R. Hinchliffe, and M. Balls, eds. Cambridge University Press, Cambridge, pp. 71-86.

Shellswell, G.B., A.J. Bailey, V.C. Duance, and D.J. Restall 1980 Has collagen a role in muscle pattern formation in the developing chick wing? I. An immunofluorescence study. J. Embryol. Exp. Morphol., 60:245-254

Shimizu, T., J.E. Dennis, T. Masaki, and D.A. Fischman 1985 Axial arrangement of the myosin rod in vertebrate thick filaments: immunoelectron microscopy with a monoclonal antibody to light meromyosin. J. Cell Biol., 101:1115-1123.

Singley, C.T., and M. Solursh 1981 The spatial distribution of hyaluronic acid and mesenchymal condensation in the embryonic chick wing. Dev. Biol., 84:102-120.

Sorrell, J.M., S. Mahmoodian, and B. Caterson 1988 Immunochemical and biochemical comparisons between embryonic chick bone marrow and epiphyseal cartilage chondroitin/dermatan sulfate proteoglycans. J. Cell Sci., 91:81-90.

Steinberg, M.S. 1970 Does differential adhesion govern self-assembly processes in histogenesis? Equilibrium configurations and the emergence of a hierarchy among populations of embryonic cells. J. Exp. Zool., 173:395-434.

Sullivan, G.E. 1962 Anatomy and embryology of the wing musculature of the domestic fowl (Gallus). Aust. J. Zool., 10:458-518.

Sweeney, L.J., J.M. Kennedy, R. Zak, K. Kokjohn, and S.W. Kelley 1989 Evidence for expression of a common myosin heavy chain phenotype in future fast and slow skeletal muscle during initial stages of avian embryogenesis. Dev. Biol., 133:361-374

Tanaka, H., and L.T. Landmesser 1986 Interspecies selective motoneuron projection patterns in chick-quail chimeras. J. Neurosci., 6:2880-2888.

Thaller, C., and G. Eichele 1987 Identification and spatial distribution of retinoids in the developing chick limb bud. Nature, 327 : $625-628$.

Thorogood, P.V., and J.R. Hinchliffe 1975 An analysis of the condensation process during chondrogenesis in the embryonic chick hind limb. J. Embryol. Exp. Morphol., 33:581-606.

Tickle, C., A. Crawley, and M. Goodman 1978 Cell movement and the mechanism of invasiveness. A survey of the behavior of some normal and malignant cells implanted into the developing chick wing bud. J. Cell Sci.,. 31:293-322.

Toole, B.P., 1972 Hyaluronate turnover during chondrogenesis in the developing chick limb and axial skeleton. Dev. Biol., 29:321-329.

Tosney, K.W., and L.T. Landmesser 1986 Neurites and growth cones in the chick embryo: enhanced tissue preservation and visualization of HRP-labeled subpopulations in serial $25 \mu \mathrm{m}$ plastic sections cut on a rotary microtome. J. Histochem. Cytochem., 34 . 953-957.

Turner, D.C. 1986 Cell-cell and cell-matrix interactions in the morphogenesis of skeletal muscle In: Development Biology, Vol. 3 , M.S. Steinberg, ed. Plenum, New York, pp. 205-224.

Weston, J.A., K.S. Vogel, and M.F. Marusich 1988 Identification and fate of neural crest subpopulations in early embryonic development. In: From Message to Mind, S.S. Easter, K.F. Barald, and B.M. Carlson, eds. Sinauer, Sunderland, MA, pp. 224-237.

Wilson, D.J. 1986 Development of avascularity during cartilage differentiation in the embryonic limb. Differentiation, 30:183-187.

Wolpert, L. 1969 Positional information and the spatial pattern of cellular differentiation. J. Theor. Biol., 25:1-47.

Wortham, R. 1948 The development of the muscles and tendons in the lower leg and foot of chick embryos. J. Morphol., 83:105-148. 